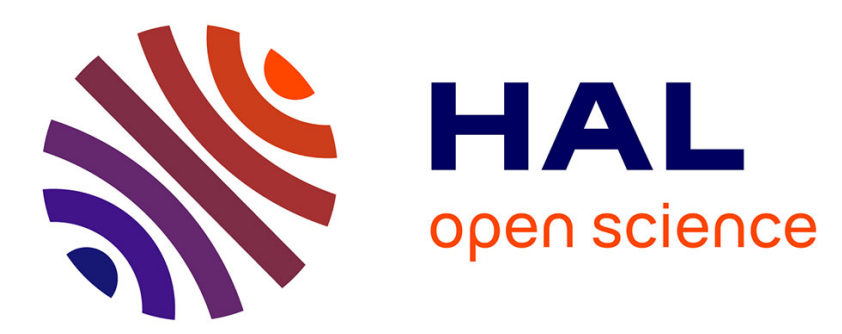

\title{
Vibrational and electronic collisional-radiative model in CO2-N2-Ar mixtures for Mars entry problems
}

\author{
Julien Annaloro, Arnaud Bultel
}

\section{To cite this version:}

Julien Annaloro, Arnaud Bultel. Vibrational and electronic collisional-radiative model in CO2-N2-Ar mixtures for Mars entry problems. Physics of Plasmas, 2019, 26 (10), pp.103505. 10.1063/1.5114792 . hal-02314382

\section{HAL Id: hal-02314382 \\ https://hal.science/hal-02314382}

Submitted on 3 Jun 2021

HAL is a multi-disciplinary open access archive for the deposit and dissemination of scientific research documents, whether they are published or not. The documents may come from teaching and research institutions in France or abroad, or from public or private research centers.
L'archive ouverte pluridisciplinaire HAL, est destinée au dépôt et à la diffusion de documents scientifiques de niveau recherche, publiés ou non, émanant des établissements d'enseignement et de recherche français ou étrangers, des laboratoires publics ou privés. 


\title{
Vibrational and electronic collisional-radiative model in $\mathrm{CO}_{2}-\mathrm{N}_{2}$-Ar mixtures for Mars entry problems
}

\author{
Cite as: Phys. Plasmas 26, 103505 (2019); doi: 10.1063/1.5114792 \\ Submitted: 11 June 2019 - Accepted: 4 September 2019 . \\ Published Online: 11 October 2019 \\ Julien Annaloro ${ }^{1,2, a)}$ and Arnaud Bultel ${ }^{2, b)}$ (D)

\begin{abstract}
AFFILIATIONS
${ }^{7}$ CNES, 18 Avenue Edouard Belin, 31401 Toulouse Cedex 9, France

${ }^{2}$ CORIA-UMR 6614, Normandie Université, CNRS-Université et INSA de Rouen, Campus Universitaire du Madrillet, 76800 Saint-Etienne du Rouvray Cedex, France

a)Electronic mail: Julien.Annaloro@cnes.fr

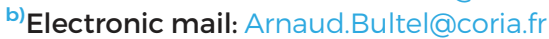

\begin{abstract}
To predict the nonequilibrium flows around a hypersonic vehicle entering the Martian atmosphere, the two-temperature collisional-radiative model "CoRaM-MARS" has been developed. The species $\mathrm{CO}_{2}, \mathrm{CO}, \mathrm{C}_{2}, \mathrm{CN}, \mathrm{N}_{2}, \mathrm{NO}, \mathrm{O}_{2}, \mathrm{C}, \mathrm{N}, \mathrm{O}, \mathrm{Ar}, \mathrm{CO}^{+}, \mathrm{C}_{2}^{+}, \mathrm{CN}^{+}, \mathrm{N}_{2}^{+}, \mathrm{NO}^{+}, \mathrm{O}_{2}^{+}, \mathrm{C}^{+}$, $\mathrm{N}^{+}, \mathrm{O}^{+}, \mathrm{Ar}^{+}$, and free electrons are taken into account. The model can therefore be used for conditions belonging to wide ranges of temperatures and pressures. The model is vibrationally specific on the ground electronic state of $\mathrm{CO}_{2}, \mathrm{CO}, \mathrm{C}_{2}, \mathrm{CN}, \mathrm{N}_{2}, \mathrm{NO}$, and $\mathrm{O}_{2}$ and electronically specific for all species, with a total of almost 445 vibrational states and 1139 electronic states, respectively. Due to the high temperatures involved $(\sim 40000 \mathrm{~K})$, a wide set of elementary processes is considered under electron and heavy particle impact reaching $\sim 10^{6}$ forward and backward elementary processes. The model is implemented in a 1D Eulerian code simulating the shock crossing of the hypersonic flow in the conditions of the entry of the EXOMARS Schiaparelli module into the Martian atmosphere.
\end{abstract}

Published under license by AIP Publishing. https://doi.org/10.1063/1.5114792

\section{INTRODUCTION}

Since the 1990s, significant works have been devoted to the statedependent rate coefficient determination. In addition, the computational resources have been substantially improved. It is now possible to elaborate chemical mechanisms at the state level. In the general framework of the next Martian missions dedicated to the ground exploration by probes after a successful landing, the elaboration of a new collisional-radiative (CR) model, able to simulate the complex chemistry of (a) the formation-relaxation of the shock layer in the front of the Thermal Protection System (TPS) of an entering body and (b) the recombination phase close to the after-body, is mandatory to thoroughly estimate the excited state population densities and the resulting radiative fluxes. The present paper aims at presenting this new model called CoRaM-MARS. Its elaboration has been performed similar to our former CoRaM-AIR model. ${ }^{1}$ Due to the $\mathrm{CO}_{2}-\mathrm{N}_{2}-\mathrm{Ar}$ mixture concerned by the Martian entries, the present model is richer than CoRaM-AIR in terms of excited states. Beyond the vibrational approach used to describe the behavior of the diatomic molecules, one main interest of the present model is the detailed treatment performed for the vibration of $\mathrm{CO}_{2}$ for which (a) the three modes are separated and (b) the different vibrational excited states are considered as full species and behave freely.

This new model has been implemented in a 1D Eulerian computational fluid dynamics (CFD) code. The relaxation of the mixture is studied in the downstream conditions of a shock produced by the hypersonic entry of the EXOMARS Schiaparelli module into the Martian atmosphere. ${ }^{2}$ We assume that the mixture is characterized by two translational temperatures $\left(T_{A}\right.$ for heavy particles and $T_{e}$ for electrons) in thermal nonequilibrium $\left(T_{e} \neq T_{a}\right)$. The electron and heavy particle-induced collisional elementary processes as well as the radiative elementary processes are thoroughly discussed in Sec. II. As far as the missing data are concerned, relevant assumptions are proposed. After the presentation of the database, the specific behaviors of the mixture are analyzed in reference situations. The discussion is focused on the consequences of thermal nonequilibrium on the dissociationionization situations. This discussion is provided in Sec. III. The dynamics of the vibrational distributions is analyzed. Those related to the electronic excited states responsible for the radiative signature of 
the plasma are also discussed. Finally, we focus our attention on the vibrational distribution of the three modes of $\mathrm{CO}_{2}$.

\section{CoRAM-MARS COLLISIONAL-RADIATIVE MODEL}

\section{A. Involved species, database}

We have adopted an approach similar to that developed in our model devoted to air. ${ }^{1}$ The diatomic molecules have been considered on each vibrational state on their electronic ground state $X$. However, for $\mathrm{CO}_{2}$, the situation is more tricky. Indeed, considering $\mathrm{CO}_{2}$ with the same approach would lead to too many vibrational states owing to the three vibrational modes of this molecule. A rapid estimate has led to about 7500 states assuming a behavior of the harmonic oscillator type and to about 10000 states assuming that the $\mathrm{CO}_{2}$ molecules behave like anharmonic oscillators. We have therefore considered a complementary approach for which $\mathrm{CO}_{2}$ molecules are assumed to be harmonic oscillators and separated in two sets according to their vibrational excitation energy. The first set is denoted as $G_{1}$ group molecules whose vibrational energy is lower than a certain threshold $E_{v}^{G_{1} \rightarrow G_{2}}=0.8 \mathrm{eV}$. The choice of $E_{v}^{G_{1} \rightarrow G_{2}}$ results from the rate coefficients reported in the literature (see Sec. II B 1). In group $G_{1}$, the molecules can be simultaneously excited in their different vibrational modes. The related vibrational states are labeled $\left(v_{1} v_{2} v_{3}\right)$ where $v_{1}, v_{2}$, and $v_{3}$ are the vibrational quantum numbers relative to the symmetric stretching mode, to the bending mode, and to the asymmetric mode, respectively. The influence of the quantum number $l_{2}$ resulting from the vibrational bending ${ }^{3}$ has been totally ignored, except for the calculation of the degeneracy of the bending mode excited levels. Beyond the threshold $E_{v}^{G_{1} \rightarrow G_{2}}$, the second set $G_{2}$ groups the $\mathrm{CO}_{2}$ molecules that can be considered to be excited in any vibrational mode but with the other modes totally deactivated. The related vibrational states are labeled $\left(v_{1} 00\right),\left(0 v_{2} 0\right)$, or $\left(00 v_{3}\right)$. Using this approach, the global dissociation rate coefficient of $\mathrm{CO}_{2}$ under self-impact has been estimated and matches rather well the experimental results over the range of $3000 \mathrm{~K}<T_{A}<7000 \mathrm{~K}^{4,5}$ This approach is more detailed than the one developed by Kozak and Bogaerts ${ }^{6}$ but simpler than the one used by Silva et al. ${ }^{7}$ or Berthelot and Bogaerts ${ }^{8}$ since these last authors have also considered the (quadratic) coupling between harmonic oscillators. The model for $\mathrm{CO}_{2}$ has been finally enriched by the triplet states ${ }^{3} \Sigma_{u}^{+},{ }^{3} \Delta_{u},{ }^{3} \Sigma_{u}^{-}$to have a global view of the electronic excitation of this molecule. The part of the concerned energy diagram is reported in Fig. 1.

The chemistry of the mixture can lead to the formation of numerous compounds. The 21 species concerned $\mathrm{CO}_{2}, \mathrm{CO}, \mathrm{C}_{2}, \mathrm{CN}$, $\mathrm{N}_{2}, \mathrm{NO}, \mathrm{O}_{2}, \mathrm{C}, \mathrm{N}, \mathrm{O}, \mathrm{Ar}, \mathrm{CO}^{+}, \mathrm{C}_{2}^{+}, \mathrm{CN}^{+}, \mathrm{N}_{2}^{+}, \mathrm{NO}^{+}, \mathrm{O}_{2}^{+}, \mathrm{C}^{+}, \mathrm{N}^{+}, \mathrm{O}^{+}$, and $\mathrm{Ar}^{+}$are detailed in Table I. Each vibrational state is considered for the molecules on their electronic ground state. Otherwise, the molecules are treated only on their electronic excitation, as for the atoms and atomic ions. The concerned energy diagram has been taken from the NIST database for the atoms and the atomic ions and from the CoRaM-AIR model for the species $\mathrm{N}_{2}, \mathrm{NO}, \mathrm{O}_{2}, \mathrm{~N}_{2}^{+}, \mathrm{NO}^{+}$, and $\mathrm{O}_{2}^{+}$.

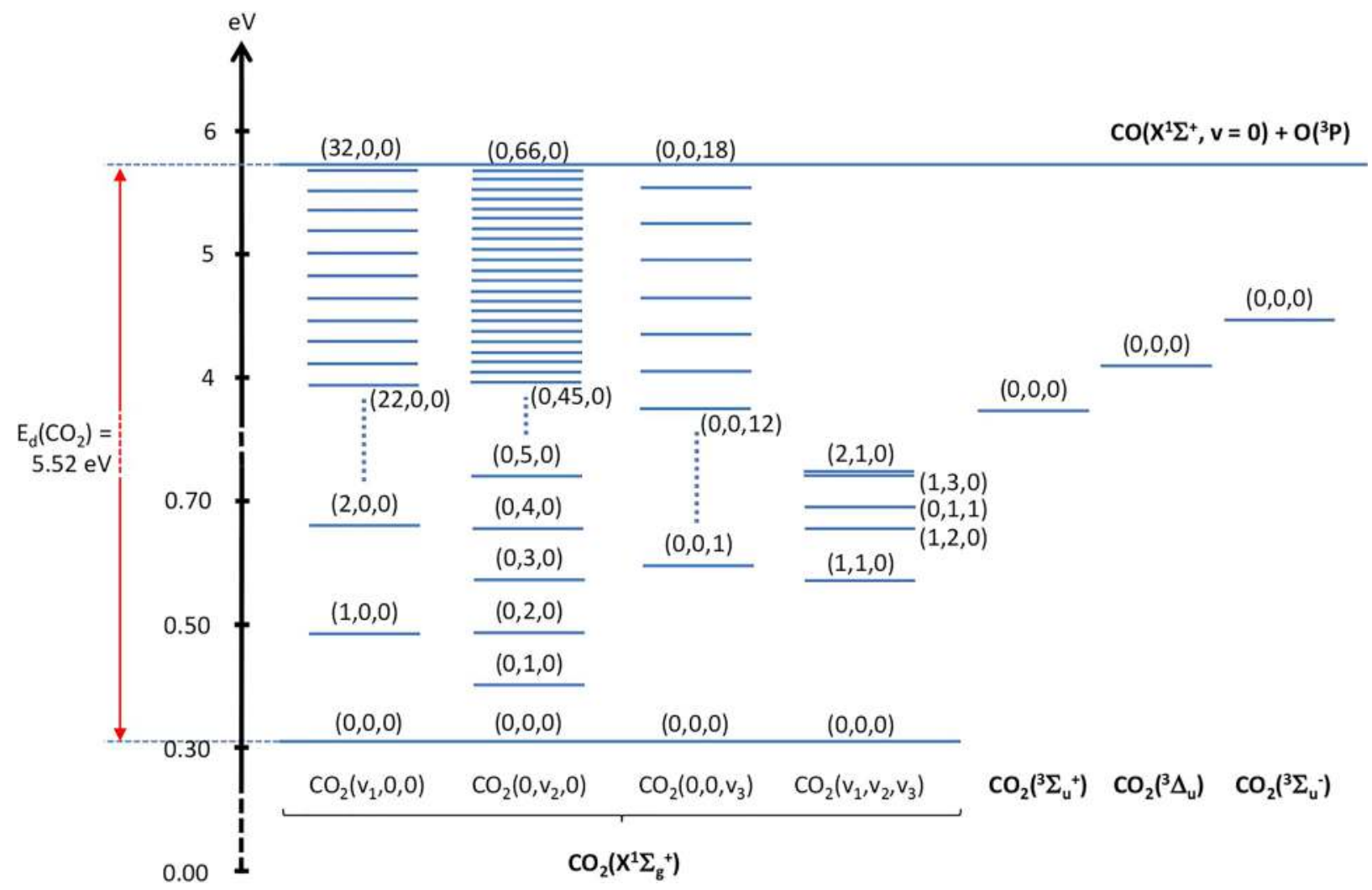

FIG. 1. Energy diagram for the $\mathrm{CO}_{2}$ molecules. 
TABLE I. Species and their different states involved in CoRaM-MARS.

\begin{tabular}{|c|c|c|}
\hline Type & Species & States \\
\hline \multirow[t]{7}{*}{ Molecules } & $\mathrm{CO}_{2}$ & $X^{1} \Sigma_{g}^{+}$(123 vibrational states), ${ }^{3} \Sigma_{u}^{+},{ }^{3} \Delta_{u},{ }^{3} \Sigma_{u}^{-}$ \\
\hline & $\mathrm{N}_{2}$ & $X^{1} \Sigma_{g}^{+}(v=0 \rightarrow 67), A^{3} \Sigma_{u}^{+}, B^{3} \Pi_{g}, W^{3} \Delta_{u}, B^{\prime 3} \Sigma_{u}^{-}, a^{\prime 1} \Sigma_{u}^{-}, a^{1} \Pi_{g}, w^{1} \Delta_{u}, G^{3} \Delta_{g}, C^{3} \Pi_{u}, E^{3} \Sigma_{g}^{+}$ \\
\hline & $\mathrm{O}_{2}$ & $X^{3} \Sigma_{g}^{-}(v=0 \rightarrow 46), a^{1} \Delta_{g}, b^{1} \Sigma_{g}^{+}, c^{1} \Sigma_{u}^{-}, A^{\prime 3} \Delta_{u}, A^{3} \Sigma_{u}^{+}, B^{3} \Sigma_{u}^{-}, f^{1} \Sigma_{u}^{+}$ \\
\hline & $\mathrm{C}_{2}$ & $X^{1} \Sigma_{g}^{+}(v=0 \rightarrow 36), a^{3} \Pi_{u}, b^{3} \Sigma_{g}^{-}, \stackrel{\circ}{A}^{1} \Pi_{u}, c^{3} \Sigma_{u}^{+}, d^{3} \Pi_{g}, C^{1} \Pi_{g}, e^{3} \Pi_{g}, D^{1} \Sigma_{u}^{+}$ \\
\hline & NO & $X^{2} \Pi(v=0 \rightarrow 53), a^{4} \Pi, A^{2} \Sigma^{+}, B^{2} \Pi, b^{4} \Sigma^{-}, C^{2} \Pi, D^{2} \Sigma^{+}, B^{\prime 2} \Delta, E^{2} \Sigma^{+}, F^{2} \Delta$ \\
\hline & $\mathrm{CO}$ & $X^{1} \Sigma^{+}(v=0 \rightarrow 76), a^{3} \Pi, a^{13} \Sigma^{+}, d^{3} \Delta, e^{3} \Sigma^{-}, A^{1} \Pi, I^{1} \Sigma^{-}, D^{1} \Delta^{-}, b^{3} \Sigma^{+}, B^{1} \Sigma^{+}$ \\
\hline & $\mathrm{CN}$ & $X^{2} \Sigma^{+}(v=0 \rightarrow 41), A^{2} \Pi, B^{2} \Sigma^{+}, D^{2} \Pi, E^{2} \Sigma^{+}, F^{2} \Delta$ \\
\hline \multirow[t]{6}{*}{ Molecular ions } & $\mathrm{N}_{2}^{+}$ & $X^{2} \Sigma_{g}^{+}, A^{2} \Pi_{u}, B^{2} \Sigma_{u}^{+}, a^{4} \Sigma_{u}^{+}, D^{2} \Pi_{g}, C^{2} \Sigma_{u}^{+}$ \\
\hline & $\mathrm{O}_{2}^{+}$ & $X^{2} \Pi_{g}, a^{4} \Pi_{u}, A^{2} \Pi_{u}, b^{4} \Sigma_{g}^{-}$ \\
\hline & $\mathrm{C}_{2}^{+}$ & $X^{4} \Sigma_{g}^{-}, 1^{2} \Pi_{u},{ }^{4} \Pi_{u}, 1^{2} \Sigma_{g}^{+}, 2^{2} \Pi_{u}, \tilde{B}^{4} \Sigma_{u}^{-}, 1^{2} \Sigma_{u}^{+}$ \\
\hline & $\mathrm{NO}^{+}$ & $X^{1} \Sigma^{+}, a^{3} \Sigma^{+}, b^{3} \Pi, W^{3} \Delta, b^{\prime 3} \Sigma^{-}, A^{\prime 1} \Sigma^{+}, W^{1} \Delta, A^{1} \Pi$ \\
\hline & $\mathrm{CO}^{+}$ & $X^{2} \Sigma^{+}, A^{2} \Pi, B^{2} \Sigma^{+}, C^{2} \Delta$ \\
\hline & $\mathrm{CN}^{+}$ & $X^{1} \Sigma^{+}, a^{3} \Pi,{ }^{1} \Delta, c^{1} \Sigma^{+}$ \\
\hline \multirow[t]{4}{*}{ Atoms } & $\mathrm{N}$ & ${ }^{4} S_{3 / 2}^{o},{ }^{2} D_{5 / 2}^{o},{ }^{2} D_{3 / 2}^{o},{ }^{2} P_{1 / 2}^{o}, \ldots$ (252 states) \\
\hline & $\mathrm{O}$ & ${ }^{3} P_{2},{ }^{3} P_{1},{ }^{3} P_{0},{ }^{1} D_{2}, \ldots$ (127 states) \\
\hline & $\mathrm{C}$ & ${ }^{3} P_{0},{ }^{3} P_{1},{ }^{3} P_{2},{ }^{1} D_{2}, \ldots$ (265 states $)$ \\
\hline & Ar & ${ }^{1} S_{0},{ }^{2}[3 / 2]_{2}^{o},{ }^{2}[3 / 2]_{1}^{o},{ }^{2}[1 / 2]_{0}^{o}, \ldots$ (379 states) \\
\hline \multirow[t]{4}{*}{ Atomic ions } & $\mathrm{N}^{+}$ & ${ }^{3} P_{0},{ }^{3} P_{1},{ }^{3} P_{2},{ }^{1} D_{2}, \ldots$ (9 states) \\
\hline & $\mathrm{O}^{+}$ & ${ }^{4} S_{3 / 2}^{o},{ }^{2} D_{5 / 2}^{o},{ }^{2} D_{3 / 2}^{o},{ }^{2} P_{3 / 2}^{o}, \ldots$ (8 states $)$ \\
\hline & $\mathrm{C}^{+}$ & ${ }^{2} P_{1 / 2}^{o},{ }^{2} P_{3 / 2}^{o},{ }^{4} P_{1 / 2},{ }^{4} P_{3 / 2}, \ldots$ (8 states) \\
\hline & $\mathrm{Ar}^{+}$ & ${ }^{2} P_{3 / 2}^{o},{ }^{2} P_{1 / 2}^{o},{ }^{2} S_{1 / 2},{ }^{4} D_{7 / 2}, \ldots$ (7 states $)$ \\
\hline
\end{tabular}

For $\mathrm{CO}, \mathrm{C}_{2}, \mathrm{CN}, \mathrm{CO}^{+}, \mathrm{C}_{2}^{+}$, and $\mathrm{CN}^{+}$, the energy diagram is derived from the data reported in Refs. 9-19. CoRaM-MARS considers a total of 445 vibrational states and 1139 electronic states.

\section{B. Elementary processes}

The mixture is considered to be in thermal nonequilibrium. The electron energy distribution function is assumed Maxwellian at $T_{e}$ as a result of the efficiency of the elastic collisions. In contrast to the case of discharges, ${ }^{20,21}$ no electric field is involved in the present flow conditions and the density is assumed sufficiently high to induce the thermalization of electrons. This assumption avoids the resolution of the Boltzmann equation whose treatment would be time-consuming owing to the high number of states involved. The electron temperature $T_{e}$ is assumed different from the kinetic temperature $T_{A}$. In addition, the rotational mode of the molecules is assumed driven by heavy particle-induced collisions according to time scales shorter than those of the temporal evolutions put forward in Secs. III D and III E. As a result, the rotational distribution is assumed Boltzmannian at $T_{A}$. Although previous works ${ }^{22}$ have clearly showed that rotation departs from a Boltzmann distribution, this assumption seems justified regarding the calculations performed by Panesi et al. ${ }^{23,24}$ already discussed for air. ${ }^{1}$ The distance required to reach a rotational equilibrium is $x_{R}=u \tau_{R}^{\prime} n^{\prime} / n$, where $\tau_{R}^{\prime}=2 \times 10^{-7} \mathrm{~s}, n^{\prime}=7.2 \times 10^{22} \mathrm{~m}^{-3}$, and $n$ is the density of the present case. We will see in Sec. III D 1 that $u$ $\sim 600 \mathrm{~m} \mathrm{~s}^{-1}$ and $n \sim 4 \times 10^{22} \mathrm{~m}^{-3}$. This leads to $x_{R} \sim 2 \times 10^{-4} \mathrm{~m}$ and corresponds to positions close to the shock front. Regarding the specific abscissa where dissociation takes place (see Sec. III D 2), the assumption of a Boltzmann distribution for rotation is justified.
All elementary processes taken into account in CoRaM-AIR have been considered in the present model. ${ }^{1}$ The related rate coefficients have been reused. In Secs. II B 1-II B 4, we therefore expose the model concerning the additional species only.

\section{Vibrational processes and dissociation}

We first discuss hereafter the case of $\mathrm{CO}_{2}$. The model has been elaborated to be used even at low pressure. As a result, the perfect coupling between the first and second vibrational modes of $\mathrm{CO}_{2}$ through the Fermi resonance

$$
\mathrm{CO}_{2}(100)+\mathrm{M} \rightarrow \mathrm{CO}_{2}(020)+\mathrm{M}
$$

may not be systematically observed. We have therefore considered a finite collisional rate for process (1) denoted as $k_{F R}$. As far as we know, no estimate of this rate coefficient has been experimentally performed at temperature higher than $300 \mathrm{~K}^{25}$ We have therefore used the approach described by Herzfeld ${ }^{26}$ to obtain the rate coefficient at higher temperature. The results of this approach have been successfully used by Blauer and Nickerson ${ }^{27}$ to evaluate numerous rate coefficients involving $\mathrm{CO}_{2}$ molecules of similar vibrational energy grouped at fictitious levels. The rate coefficient of the Fermi resonance (1) is displayed in Fig. 2. It is important to mention that the rate coefficient weakly depends on $T_{A}$. The values are very close to $3 \times 10^{-17} \mathrm{~m}^{3} \mathrm{~s}^{-1}$ over the range of $1000 \mathrm{~K}<T_{A}<10000 \mathrm{~K}$. Joly and Roblin ${ }^{25}$ reviewed the experimental values of this rate coefficient, available at $300 \mathrm{~K}$ only. The value of $3 \times 10^{-17} \mathrm{~m}^{3} \mathrm{~s}^{-1}$ belongs to the experimental interval. As a result, the rate coefficient displayed in Fig. 2 has been used for 


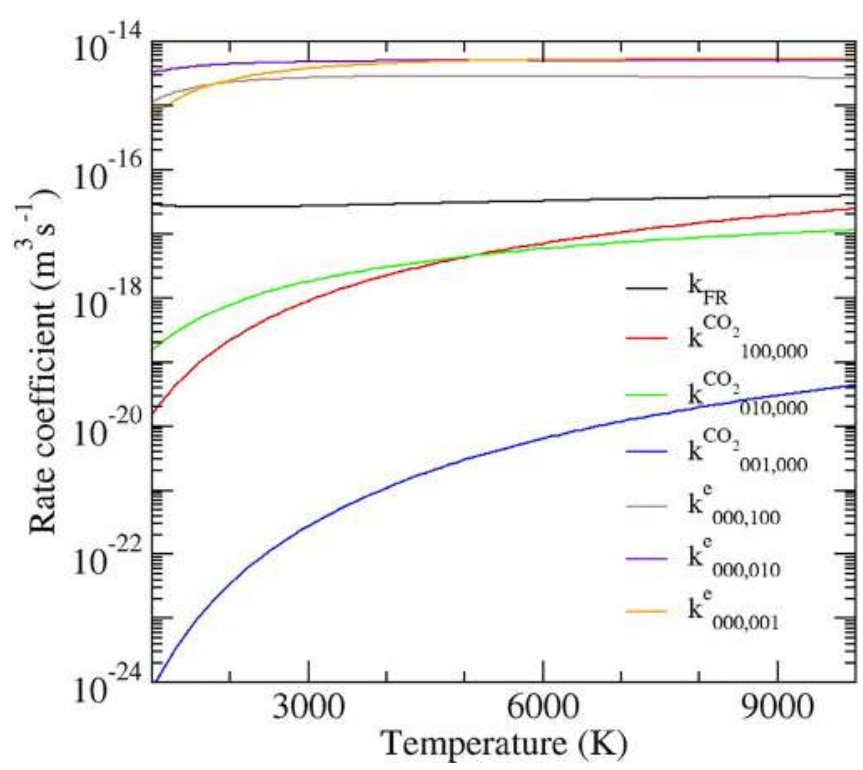

FIG. 2. Temperature dependent rate coefficients $k_{F R}, k_{100.000}^{\mathrm{CO}_{2}}, k_{010.000}^{\mathrm{CO}_{2}}, k_{001.000}^{\mathrm{CO}_{2}}$, $k_{000,100}^{e}, k_{000,010}^{e}$, and $k_{000,001}^{e}$ for the Fermi resonance (1) and the deexcitation processes (2)-(4) and (5)-(7), respectively.

process (1) and for the Fermi resonance arising between molecules if their vibrational energy difference is less than $0.02 \mathrm{eV}$.

Herzberg's approach has also been used to determine the rate coefficient of the vibration-translation (VT) process under atomic or molecular impact,

$$
\begin{aligned}
& \mathrm{CO}_{2}(100)+\mathrm{M} \rightarrow \mathrm{CO}_{2}(000)+\mathrm{M} \\
& \mathrm{CO}_{2}(010)+\mathrm{M} \rightarrow \mathrm{CO}_{2}(000)+\mathrm{M}, \\
& \mathrm{CO}_{2}(001)+\mathrm{M} \rightarrow \mathrm{CO}_{2}(000)+\mathrm{M}
\end{aligned}
$$

The evolution with temperature of the related rate coefficients $k_{100,000}^{\mathrm{M}}, k_{010,000}^{\mathrm{M}}$, and $k_{001,000}^{\mathrm{M}}$ is displayed in Fig. 2 for $\mathrm{M} \equiv \mathrm{CO}_{2}$. For the other collision partners, each rate coefficient is multiplied by the collision efficiency $\eta_{\mathrm{M}}$ with the M-dependent value ${ }^{27} \eta_{\mathrm{CO}_{2}}=\eta_{\mathrm{O}}=1$ and $\eta_{\mathrm{CO}}=\eta_{\mathrm{N}_{2}}=\eta_{\mathrm{O}_{2}}=0.7$. The process has been neglected for the other collision partners. The extrapolation at higher vibrational excitation energy is assumed to be driven by the SSH (Schwartz-SlawskyHerzfeld) theory. ${ }^{28}$ No multiquanta jump has been considered.

For the other VT processes, especially those involving the $v_{1} v_{2}$ $v_{3}$ ) levels, rate coefficients have been mainly calculated by Blauer and Nickerson $^{27}$ from Herzberg's approach. We have recalculated these rate coefficients since Blauer and Nickerson have considered fictitious levels grouping molecules of similar vibrational energy. This procedure has been also performed for the inter- and intra-vibration-vibration $(\mathrm{VV})$ processes.

The levels of $\mathrm{CO}_{2}$ molecules can also be populated by the vibration-electron $(\mathrm{Ve})$ elementary processes such as

$$
\begin{aligned}
& \mathrm{CO}_{2}(000)+\mathrm{e}^{-} \rightarrow \mathrm{CO}_{2}(100)+\mathrm{e}^{-}, \\
& \mathrm{CO}_{2}(000)+\mathrm{e}^{-} \rightarrow \mathrm{CO}_{2}(010)+\mathrm{e}^{-}, \\
& \mathrm{CO}_{2}(000)+\mathrm{e}^{-} \rightarrow \mathrm{CO}_{2}(001)+\mathrm{e}^{-} .
\end{aligned}
$$

These excitation processes under electron impact have been experimentally studied by several authors whose results have been reviewed by Itikawa. ${ }^{29}$ The mean behavior of the cross sections has been considered to derive the rate coefficients $k_{000,100}^{\mathrm{e}}, k_{000,010}^{\mathrm{e}}$, and $k_{000,001}^{\mathrm{e}}$ whose temperature dependence is displayed in Fig. 2. The generalization of these processes at higher vibrational excitation has been performed using the procedure recommended by Fridman ${ }^{30}$ valid not only for diatomic molecules but also for triatomic molecules. Using this procedure, the rate coefficient for any vibrational excitation $v \rightarrow$ $v^{\prime}$ under electron impact is proportional to the rate of the $0 \rightarrow 1$ excitation modulated by a relatively simple function of $v$ and $v^{\prime}$.

As for diatomic molecules, we have assumed that the dissociation of the $\mathrm{CO}_{2}$ molecules is the result of the excitation of a virtual vibrational state $v_{\max }+1$ close to the last bound levels $\left(v_{1}^{\max } 00\right),\left(0 v_{2}^{\max } 0\right)$, and $\left(00 v_{3}^{\max }\right)$ since $T_{A}$ is at a maximum value of $\sim 15000 \mathrm{~K}$ during the dissociation. ${ }^{31}$ This excitation may be due to the impact of molecules pumping those of the level $v_{\max }$ or to that of atoms pumping molecules of any vibrational level. These assumptions are the same as those considered in CoRaM-AIR, and the rate coefficients considered in Ref. 1 have been reused.

For the $\mathrm{CO}, \mathrm{CN}$, and $\mathrm{C}_{2}$ molecules, vibrational processes have also been taken into account. VT processes under molecular (VT-m) and atomic (VT-a) impact are implemented in CoRaM-MARS. (VV) exchanges can also play a significant role as well as $(\mathrm{Ve})$ elementary processes. Table II summarizes these processes. As far as we know, no result has been published on the $\mathrm{CO}$ and $\mathrm{N}_{2}$ vibrational de-excitation under $\mathrm{CO}_{2}$ and $\mathrm{CO}$ molecule impact, respectively. We have therefore assumed that the related rate coefficients are similar to those of the $\mathrm{CO}$ vibrational de-excitation under $\mathrm{CO}$ impact and the $\mathrm{N}_{2}$ vibrational de-excitation under $\mathrm{N}_{2}$ impact reported in Refs. 32 and 33, respectively. These rate coefficients are corrected by the square root of the reduced mass ratio resulting from the fact that the collision partner has changed. It is also important to mention that the elementary data about $\mathrm{CN}$ and $\mathrm{C}_{2}$ are lacking. Analogies are consequently to be done. The spectroscopic constant $\omega_{e}$ of $\mathrm{C}_{2}$ and $\mathrm{CN}$ is close to that of $\mathrm{NO}$ and $\mathrm{CO}$, respectively. As a result, the rate coefficients of VT deexcitation $v=1 \rightarrow 0$ of $\mathrm{C}_{2}$ and $\mathrm{CN}$ have been assumed to be equal to those of the equivalent processes involving $\mathrm{NO}$ and $\mathrm{CO}$, respectively. The extrapolation over the vibrational distribution is performed by using a scaling function estimated from the SSH theory, modified for an anharmonic vibrational distribution. ${ }^{32}$ For the $(\mathrm{Ve})$ processes of $\mathrm{C}_{2}$ and $\mathrm{CN}$, we have assumed the same $v=0 \rightarrow 1$ excitation rate coefficient as for $\mathrm{NO}$ and for $\mathrm{CO}$, respectively. These $v=0 \rightarrow 1$ excitation rate coefficients have been calculated by Laporta et al. ${ }^{34,35}$ The electron energy range concerned by the results displayed in Secs. III D and III E corresponds approximately to the resonance with the associated anion. For $\mathrm{N}_{2}$, the agreement between the experimental results and those obtained by Laporta et al. assuming only the resonant channel are quite satisfactory until electron energies are $\sim 5 \mathrm{eV}$. ${ }^{36}$ We have therefore neglected the nonresonant channel. The extrapolation over the vibrational distribution is performed using the approach proposed by Fridman. $^{30}$

The rate coefficients for the dissociation of the excited $\mathrm{CO}, \mathrm{CN}$, $\mathrm{C}_{2}, \mathrm{CO}^{+}, \mathrm{CN}^{+}$, and $\mathrm{C}_{2}^{+}$molecules have been taken from the work of Park, ${ }^{37}$ Gorelov et al., ${ }^{38}$ and Lecointre et al. ${ }^{39}$ For the dissociation of diatomic molecules not reported in the previous references, we have taken the rate coefficients estimated in our previous work. ${ }^{1,40}$ 
TABLE II. Vibrational processes implemented in CoRaM-MARS involving $\mathrm{CO}, \mathrm{CN}$, and $\mathrm{C}_{2}$ and additional $\mathrm{N}_{2}(v)$ and $\mathrm{NO}(v)$ elementary processes with respect to CoRaM-AIR.

\begin{tabular}{lcccc}
\hline \hline Processes & Reactions & References & Processes & Reactions \\
\hline VT-m & $\mathrm{CO}(v)+\mathrm{CO} \rightarrow \mathrm{CO}(v-1)+\mathrm{CO}$ & 32 & $\mathrm{VT}-\mathrm{a}$ & $\mathrm{CO}(v)+\mathrm{O} \rightarrow \mathrm{CO}(v-1)+\mathrm{O}$ \\
& $\mathrm{CO}(v)+\mathrm{N}_{2} \rightarrow \mathrm{CO}(v-1)+\mathrm{N}_{2}$ & 75 & & $\mathrm{C}_{2}(v)+\mathrm{O} \rightarrow \mathrm{C}_{2}(v-1)+\mathrm{O}$ \\
& $\mathrm{CO}(v)+\mathrm{CO}_{2} \rightarrow \mathrm{CO}(v-1)+\mathrm{CO}_{2}$ & $32^{\mathrm{b}}$ & & $\mathrm{CN}(v)+\mathrm{O} \rightarrow \mathrm{CN}(v-1)+\mathrm{O}$ \\
$\mathrm{NO}(v)+\mathrm{CO} \rightarrow \mathrm{NO}(v-1)+\mathrm{CO}$ & 75 & & \\
& $\mathrm{~N}_{2}(v)+\mathrm{CO} \rightarrow 2_{2}(v-1)+\mathrm{CO}$ & $33^{\mathrm{b}}$ & & \\
$\mathrm{VV}$ & $\mathrm{CO}(v)+\mathrm{CO}(w-1) \rightarrow \mathrm{CO}(v-1)+\mathrm{CO}(w)$ & 32 & $V e$ & $\mathrm{CO}(v)+e^{-} \rightarrow \mathrm{CO}(w>v)+e^{-}$ \\
& $\mathrm{CO}(v)+\mathrm{N}_{2}(w-1) \rightarrow \mathrm{CO}(v-1)+\mathrm{N}_{2}(w)$ & 75 & & $\mathrm{C}_{2}(v)+e^{-} \rightarrow \mathrm{C}_{2}(w>v)+e^{-}$ \\
& $\mathrm{NO}(v)+\mathrm{CO}(w-1) \rightarrow \mathrm{NO}(v-1)+\mathrm{CO}(w)$ & 75 & & $\mathrm{CN}^{-}(v)+e^{-} \rightarrow \mathrm{CN}^{\mathrm{a}}(w>v)+e^{-}$ \\
\hline \hline
\end{tabular}

${ }^{\mathrm{a}} \mathrm{NO}$ analogy based on similar $\omega_{e}$ values.

${ }^{\mathrm{b}}$ Reduced mass ratio correction.

${ }^{\mathrm{c}} \mathrm{CO}$ analogy based on similar $\omega_{e}$ values

Under heavy particle impact, the dissociation rate coefficient depends on the vibrational excitation of the excited molecule concerned. Since the vibrationally specific approach is used for the ground electronic states only, an assumption is done about the vibrational distribution of the excited electronic states of $\mathrm{CO}_{2}, \mathrm{CO}, \mathrm{CN}$, and $\mathrm{C}_{2}$. We assumed that this distribution is Boltzmannian with the vibrational temperature $T_{v}$ calculated as the excitation temperature of the first five vibrational states of the ground electronic state of the related molecule. This excitation temperature can be considered as a "vibrational temperature" if the calculated distribution is not too far from a Boltzmann distribution. The dissociation rate coefficient under heavy particle impact is then assumed driven by the correction of Krivonosova et al. ${ }^{41}$

The rate coefficients reported by the literature are often related to electronic states without information about the vibrational state dependence. Starting from the rate coefficient $k$ for the whole distribution, we use the Vibrational Reallocation Procedure (VRP) to derive the vibrationally dependent rate coefficient $k_{v}{ }^{1,42}$

Regarding the noncarbonated molecules, all the collisional model of Refs. 1 and 42 has been completely reused, including, in particular, the multiquanta transitions. ${ }^{43-45}$

\section{Electronic excitation and ionization}

a. Molecular species. The ionization rate coefficient under heavy particle impact has been calculated using Eq. (12) of our paper, ${ }^{1}$ whereas that under electron impact has been calculated using Eq. (13) of the same paper. The excitation from the ground state $X^{1} \Sigma_{g}^{+}$has been calculated using Eq. (12) for the heavy particle-induced collisions ${ }^{1}$ and Eq. (14) for the electron-induced collisions since the transition is optically forbidden. ${ }^{1}$ Some rate coefficients are listed in Table III.

The electronic excitation of $\mathrm{N}_{2}, \mathrm{O}_{2}, \mathrm{NO}$, and $\mathrm{N}_{2}^{+}$under $\mathrm{CO}$ impact has been derived from the work of Park. ${ }^{37}$ The work of Surzhikov, ${ }^{46}$ Zalogin et al., ${ }^{47}$ and Park ${ }^{37}$ have been used concerning the electronic excitation of $\mathrm{CO}, \mathrm{CN}$, and $\mathrm{C}_{2}$ for a part of the excited states listed in Table I. Again, the lack of data for $\mathrm{CN}$ and $\mathrm{C}_{2}$ has to be underlined. For the other states, the rate coefficient numbered (12) in our paper ${ }^{1}$ devoted to air has been used and some of them are reported in Table III.
The same procedure has been performed for processes under electron impact. The work of Riahi et al., ${ }^{48}$ Olszewski et al.,${ }^{49}$ Brunger and Buckman, ${ }^{50}$ Zalogin et al., ${ }^{47}$ Park, ${ }^{51}$ and Freund et al. ${ }^{52}$ have been used for $\mathrm{CO}, \mathrm{CN}, \mathrm{C}_{2}^{+}$, and $\mathrm{CO}$. For the rate coefficient relative to excited states not reported in the previous papers, we have used the analytical forms numbered (13) and (14) of our paper ${ }^{1}$ devoted to air for allowed and forbidden transitions, respectively.

b. Atomic species. For $\mathrm{C}$ and $\mathrm{C}^{+}$, the formalism due to Drawin ${ }^{53}$ has been used since the experimental results are scarce. The relevance of the cross-sectional set proposed by Drawin has been in part validated by the calculation of global ionization and recombination rate coefficients whose values are in relatively good agreement with experimental results. ${ }^{54}$

\section{Neutral exchange}

The rate coefficient for the carbonated species has been treated in the following way. The rate coefficients of the exchange processes,

$$
\begin{aligned}
& \mathrm{C}_{2}(d)+\mathrm{O} \rightarrow \mathrm{CO}(X)+\mathrm{C}, \\
& \mathrm{O}_{2}(X)+\mathrm{C} \rightarrow \mathrm{CO}(a)+\mathrm{O},
\end{aligned}
$$

are due to Aliat ${ }^{55}$ and to the interpolation used in the GriMech 3.0 chemical mechanism ${ }^{56}$ over the range of $300 \mathrm{~K}<T_{A}<3000 \mathrm{~K}$, respectively. We have considered that the latter rate coefficient can be used at higher temperature. From these values, those for the processes,

$$
\begin{aligned}
& \mathrm{C}_{2}(i)+\mathrm{O} \rightarrow \mathrm{CO}(j)+\mathrm{C}, \\
& \mathrm{O}_{2}(i)+\mathrm{C} \rightarrow \mathrm{CO}(j)+\mathrm{O},
\end{aligned}
$$

have been determined by using the following assumptions. The elementary rate coefficient presents a modified Arrhenius form of the type $k(T)=A T^{\alpha} e^{-\Delta E_{X X^{\prime}} /\left(k_{B} T\right)}$, where $\Delta E_{X X^{\prime}}$ is equal to the threshold energy if the process is inelastic or is equal to zero elsewhere. The process occurs to satisfy the Wigner and Witmer ${ }^{57}$ rule of correlation of spin and orbital momentum between reactive and product species (a factor of $1 / 10$ is then used if this rule is violated).

Other neutral exchange processes have been taken into account. In particular, those producing $\mathrm{CO}_{2}$ from a collision between $\mathrm{CO}$ (in particular, the backward process of the Boudouard process ${ }^{58}$ ), $\mathrm{O}_{2}$, and 
TABLE III. Parameters $A, \alpha$, and $B=\Delta E / k_{B}$ of the rate coefficient written under the modified Arrhenius form $k(T)=A T^{\alpha} e^{-\Delta E /\left(k_{B} T\right)}$ of some excitation, neutral exchange, and ionization processes under heavy particle impact implemented in CoRaM-MARS.

\begin{tabular}{|c|c|c|c|c|}
\hline \multirow[b]{3}{*}{ Elementary processes } & \multicolumn{3}{|c|}{ Parameters of the rate coefficient } & \multirow[b]{3}{*}{ References } \\
\hline & \multicolumn{3}{|c|}{$k\left(T_{A}\right)=A T_{A}^{\alpha} \exp \left(-B / T_{A}\right)$ expressed in $\mathrm{m}^{3} \mathrm{~s}^{-1}$} & \\
\hline & $A\left(\mathrm{~m}^{3} \mathrm{~s}^{-1} \mathrm{~K}^{-\alpha}\right)$ & $\alpha$ & $B(\mathrm{~K})$ & \\
\hline $\mathrm{CO}_{2}\left(X^{1} \Sigma_{g}^{+}\right)+\mathrm{CO}_{2}\left(X^{1} \Sigma_{g}^{+}\right) \rightarrow \mathrm{CO}_{2}\left({ }^{3} \Sigma_{u}^{+}\right)+\mathrm{CO}_{2}\left(X^{1} \Sigma_{g}^{+}\right)$ & $7.443 \times 10^{-26}$ & 1.069 & 40854 & Equation (12) of Ref. 1 \\
\hline $\mathrm{CO}_{2}\left(X^{1} \Sigma_{g}^{+}\right)+\mathrm{CO}_{2}\left(X^{1} \Sigma_{g}^{+}\right) \rightarrow \mathrm{CO}_{2}\left({ }^{3} \Delta_{u}\right)+\mathrm{CO}_{2}\left(X^{1} \Sigma_{g}^{+}\right)$ & $6.995 \times 10^{-26}$ & 1.078 & 45089 & Equation (12) of Ref. 1 \\
\hline $\mathrm{CO}_{2}\left(X^{1} \Sigma_{g}^{+}\right)+\mathrm{CO}_{2}\left(X^{1} \Sigma_{g}^{+}\right) \rightarrow \mathrm{CO}_{2}\left({ }^{3} \Sigma_{u}^{-}\right)+\mathrm{CO}_{2}\left(X^{1} \Sigma_{g}^{+}\right)$ & $6.467 \times 10^{-26}$ & 1.064 & 49311 & Equation (12) of Ref. 1 \\
\hline $\mathrm{CO}_{2}\left({ }^{3} \Sigma_{u}^{+}\right)+\mathrm{CO}_{2}\left(X^{1} \Sigma_{g}^{+}\right) \rightarrow \mathrm{CO}_{2}\left({ }^{3} \Delta_{u}\right)+\mathrm{CO}_{2}\left(X^{1} \Sigma_{g}^{+}\right)$ & $1.073 \times 10^{-24}$ & 1.466 & 2996 & Equation (12) of Ref. 1 \\
\hline $\mathrm{CO}_{2}\left({ }^{3} \Sigma_{u}^{+}\right)+\mathrm{CO}_{2}\left(X^{1} \Sigma_{g}^{+}\right) \rightarrow \mathrm{CO}_{2}\left({ }^{3} \Sigma_{u}^{-}\right)+\mathrm{CO}_{2}\left(X^{1} \Sigma_{g}^{+}\right)$ & $2.531 \times 10^{-25}$ & 1.408 & 6800 & Equation (12) of Ref. 1 \\
\hline $\mathrm{CO}_{2}\left({ }^{3} \Delta_{u}\right)+\mathrm{CO}_{2}\left(X^{1} \Sigma_{g}^{+}\right) \rightarrow \mathrm{CO}_{2}\left({ }^{3} \Sigma_{u}^{-}\right)+\mathrm{CO}_{2}\left(X^{1} \Sigma_{g}^{+}\right)$ & $1.067 \times 10^{-24}$ & 1.465 & 3005 & Equation (12) of Ref. 1 \\
\hline $\begin{array}{l}\mathrm{CO}_{2}(i)+\mathrm{CO}\left(X^{1} \Sigma^{+}\right) \rightarrow \mathrm{CO}_{2}(j)+\mathrm{CO}\left(X^{1} \Sigma^{+}\right) \\
\mathrm{CO}_{2}(i)+\mathrm{O}\left({ }^{3} P\right) \rightarrow \mathrm{CO}_{2}(j)+O\left({ }^{3} P\right)\end{array}$ & \multicolumn{3}{|c|}{$\begin{array}{c}k_{\mathrm{CO}_{2}(\mathrm{i})+\mathrm{CO}\left(\mathrm{X}^{1} \Sigma^{+}\right)}=1.134 \times k_{\mathrm{CO}_{2}(\mathrm{i})+\mathrm{CO}_{2}\left(\mathrm{X}^{1} \Sigma_{g}^{+}\right)} \\
k_{\mathrm{CO}_{2}(\mathrm{i})+\mathrm{O}\left({ }^{3} \mathrm{P}\right)}=1.370 \times k_{\mathrm{CO}_{2}(\mathrm{i})+\mathrm{CO}_{2}\left(\mathrm{X}^{1} \Sigma_{g}^{+}\right)}\end{array}$} & \\
\hline $\mathrm{CO}\left(X^{1} \Sigma^{+}\right)+\mathrm{CO}_{2}\left(X^{1} \Sigma_{g}^{+}\right) \rightarrow \mathrm{CO}\left(I^{1} \Sigma^{-}\right)+\mathrm{CO}_{2}\left(X^{1} \Sigma_{g}^{+}\right)$ & $1.131 \times 10^{-26}$ & 1.097 & $\begin{aligned}(x-2) \\
87895\end{aligned}$ & Equation (12) of Ref. 1 \\
\hline $\mathrm{CO}\left(X^{1} \Sigma^{+}\right)+\mathrm{CO}_{2}\left(X^{1} \Sigma_{g}^{+}\right) \rightarrow \mathrm{CO}\left(D^{1} \Delta^{-}\right)+\mathrm{CO}_{2}\left(X^{1} \Sigma_{g}^{+}\right)$ & $1.032 \times 10^{-26}$ & 1.102 & 88990 & Equation (12) of Ref. 1 \\
\hline $\mathrm{CO}\left(X^{1} \Sigma^{+}\right)+\mathrm{CO}_{2}\left(X^{1} \Sigma_{g}^{+}\right) \rightarrow \mathrm{CO}\left(a^{\prime 3} \Sigma^{+}\right)+\mathrm{CO}_{2}\left(X^{1} \Sigma_{g}^{+}\right)$ & $2.648 \times 10^{-26}$ & 1.054 & 75823 & Equation (12) of Ref. 1 \\
\hline $\mathrm{CO}\left(X^{1} \Sigma^{+}\right)+\mathrm{CO}_{2}\left(X^{1} \Sigma_{g}^{+}\right) \rightarrow \mathrm{CO}\left(d^{3} \Delta\right)+\mathrm{CO}_{2}\left(X^{1} \Sigma_{g}^{+}\right)$ & $1.678 \times 10^{-26}$ & 1.075 & 82791 & Equation (12) of Ref. 1 \\
\hline $\mathrm{CO}\left(X^{1} \Sigma^{+}\right)+\mathrm{CO}_{2}\left(X^{1} \Sigma_{g}^{+}\right) \rightarrow \mathrm{CO}\left(e^{3} \Sigma^{-}\right)+\mathrm{CO}_{2}\left(X^{1} \Sigma_{g}^{+}\right)$ & $1.235 \times 10^{-26}$ & 1.092 & 86815 & Equation (12) of Ref. 1 \\
\hline $\mathrm{CO}\left(X^{1} \Sigma^{+}\right)+\mathrm{O}\left({ }^{3} P\right) \rightarrow \mathrm{CO}(i)+O\left({ }^{3} P\right)$ & \multicolumn{3}{|c|}{$k_{\mathrm{CO}(\mathrm{i})+\mathrm{O}\left({ }^{3} \mathrm{P}\right)}=1.297 \times k_{\mathrm{CO}(\mathrm{i})+\mathrm{CO}_{2}\left(\mathrm{X}^{1} \Sigma_{g}^{+}\right)}$} & \\
\hline $\mathrm{CO}\left(X^{1} \Sigma^{+}\right)+\mathrm{CO}_{2}\left(X^{1} \Sigma_{g}^{+}\right) \rightarrow \mathrm{CO}^{+}\left(X^{2} \Sigma^{+}\right)+\mathrm{e}^{-}+\mathrm{CO}_{2}\left(X^{1} \Sigma_{g}^{+}\right)$ & $1.202 \times 10^{-28}$ & 1.817 & 14479 & Equation (12) of Ref. 1 \\
\hline $\mathrm{CN}\left(X^{2} \Sigma^{+}\right)+\mathrm{CO}\left(X^{1} \Sigma^{+}\right) \rightarrow \mathrm{CN}\left(D^{2} \Pi\right)+\mathrm{CO}\left(X^{1} \Sigma^{+}\right)$ & $3.320 \times 10^{-24}$ & 1.050 & 73953 & Equation (12) of Ref. 1 \\
\hline $\mathrm{CN}\left(X^{2} \Sigma^{+}\right)+\mathrm{CO}\left(X^{1} \Sigma^{+}\right) \rightarrow \mathrm{CN}\left(E^{2} \Sigma^{+}\right)+\mathrm{CO}\left(X^{1} \Sigma^{+}\right)$ & $2.201 \times 10^{-24}$ & 1.067 & 80608 & Equation (12) of Ref. 1 \\
\hline $\mathrm{CN}\left(X^{2} \Sigma^{+}\right)+\mathrm{CO}\left(X^{1} \Sigma^{+}\right) \rightarrow \mathrm{CN}\left(F^{2} \Delta\right)+\mathrm{CO}\left(X^{1} \Sigma^{+}\right)$ & $2.063 \times 10^{-26}$ & 1.070 & 81556 & Equation (12) of Ref. 1 \\
\hline $\mathrm{CN}\left(X^{2} \Sigma^{+}\right)+\mathrm{O}\left({ }^{3} P\right) \rightarrow \mathrm{CN}(i)+O\left({ }^{3} P\right)$ & \multicolumn{3}{|c|}{$k_{\mathrm{CN}(\mathrm{i})+\mathrm{O}\left({ }^{3} \mathrm{P}\right)}=1.167 \times k_{\mathrm{CN}(\mathrm{i})+\mathrm{CO}\left(\mathrm{X}^{1} \Sigma^{+}\right)}$} & \\
\hline $\mathrm{C}_{2}\left(X^{1} \Sigma_{g}^{+}\right)+\mathrm{CO}\left(X^{1} \Sigma^{+}\right) \rightarrow \mathrm{C}_{2}\left(a^{3} \Pi_{u}\right)+\mathrm{CO}\left(X^{1} \Sigma^{+}\right)$ & $1.150 \times 10^{-22}$ & 1.498 & 488 & Equation (12) of Ref. 1 \\
\hline $\mathrm{C}_{2}\left(X^{1} \Sigma_{g}^{+}\right)+\mathrm{CO}\left(X^{1} \Sigma^{+}\right) \rightarrow \mathrm{C}_{2}\left(b^{3} \Sigma_{g}^{-}\right)+\mathrm{CO}\left(X^{1} \Sigma^{+}\right)$ & $3.086 \times 10^{-25}$ & 1.403 & 7136 & Equation (12) of Ref. 1 \\
\hline $\mathrm{C}_{2}\left(X^{1} \Sigma_{g}^{+}\right)+\mathrm{CO}\left(X^{1} \Sigma^{+}\right) \rightarrow \mathrm{C}_{2}\left(A^{1} \Pi_{u}\right)+\mathrm{CO}\left(X^{1} \Sigma^{+}\right)$ & $2.060 \times 10^{-23}$ & 1.364 & 9885 & Equation (12) of Ref. 1 \\
\hline $\mathrm{C}_{2}\left(X^{1} \Sigma_{g}^{+}\right)+\mathrm{CO}\left(X^{1} \Sigma^{+}\right) \rightarrow \mathrm{C}_{2}\left(c^{3} \Sigma_{u}^{+}\right)+\mathrm{CO}\left(X^{1} \Sigma^{+}\right)$ & $1.325 \times 10^{-25}$ & 1.276 & 17056 & Equation (12) of Ref. 1 \\
\hline $\mathrm{C}_{2}\left(X^{1} \Sigma_{g}^{+}\right)+\mathrm{CO}\left(X^{1} \Sigma^{+}\right) \rightarrow \mathrm{C}_{2}\left(C^{1} \Pi_{g}\right)+\mathrm{CO}\left(X^{1} \Sigma^{+}\right)$ & $8.859 \times 10^{-26}$ & 1.072 & 46841 & Equation (12) of Ref. 1 \\
\hline $\mathrm{C}_{2}\left(X^{1} \Sigma_{g}^{+}\right)+\mathrm{CO}\left(X^{1} \Sigma^{+}\right) \rightarrow \mathrm{C}_{2}\left(e^{3} \Pi_{g}\right)+\mathrm{CO}\left(X^{1} \Sigma^{+}\right)$ & $7.263 \times 10^{-26}$ & 1.049 & 55493 & Equation (12) of Ref. 1 \\
\hline $\mathrm{C}_{2}\left(X^{1} \Sigma_{g}^{+}\right)+\mathrm{CO}\left(X^{1} \Sigma^{+}\right) \rightarrow \mathrm{C}_{2}\left(D^{1} \Sigma_{u}^{+}\right)+\mathrm{CO}\left(X^{1} \Sigma^{+}\right)$ & $6.450 \times 10^{-24}$ & 1.044 & 59371 & Equation (12) of Ref. 1 \\
\hline $\mathrm{C}_{2}\left(X^{1} \Sigma_{g}^{+}\right)+\mathrm{O}\left({ }^{3} P\right) \rightarrow \mathrm{C}_{2}(i)+\mathrm{O}\left({ }^{3} P\right)$ & \multicolumn{3}{|c|}{$k_{\mathrm{C}_{2}(\mathrm{i})+\mathrm{O}\left({ }^{3} \mathrm{P}\right)}=1.161 \times k_{\mathrm{C}_{2}(\mathrm{i})+\mathrm{CO}\left(\mathrm{X}^{1} \Sigma^{+}\right)}$} & \\
\hline $\mathrm{C}_{2}\left(X^{1} \Sigma_{g}^{+}\right)+\mathrm{O}\left({ }^{3} P\right) \rightarrow \mathrm{CO}\left(X^{1} \Sigma^{+}\right)+\mathrm{C}\left({ }^{3} P\right)$ & $7.760 \times 10^{-14}$ & -0.541 & 0 & Equation (12) of Ref. 1 \\
\hline $\mathrm{C}_{2}\left(X^{1} \Sigma_{g}^{+}\right)+\mathrm{O}\left({ }^{3} P\right) \rightarrow \mathrm{CO}\left(a^{3} \Pi\right)+\mathrm{C}\left({ }^{3} P\right)$ & $6.272 \times 10^{-14}$ & -0.541 & 11936 & Equation (12) of Ref. 1 \\
\hline $\mathrm{C}_{2}\left(X^{1} \Sigma_{g}^{+}\right)+\mathrm{O}\left({ }^{3} P\right) \rightarrow \mathrm{CO}\left(a^{\prime 3} \Sigma^{+}\right)+\mathrm{C}\left({ }^{3} P\right)$ & $5.331 \times 10^{-13}$ & -0.541 & 21831 & Equation (12) of Ref. 1 \\
\hline $\mathrm{C}_{2}\left(X^{1} \Sigma_{g}^{+}\right)+\mathrm{O}\left({ }^{3} P\right) \rightarrow \mathrm{CO}\left(d^{3} \Delta\right)+\mathrm{C}\left({ }^{3} P\right)$ & $1.137 \times 10^{-14}$ & -0.541 & 29406 & Equation (12) of Ref. 1 \\
\hline $\mathrm{C}_{2}\left(X^{1} \Sigma_{g}^{+}\right)+\mathrm{O}\left({ }^{3} P\right) \rightarrow \mathrm{CO}\left(e^{3} \Sigma^{-}\right)+\mathrm{C}\left({ }^{3} P\right)$ & $6.037 \times 10^{-14}$ & -0.541 & 33849 & Equation (12) of Ref. 1 \\
\hline $\mathrm{C}_{2}\left(X^{1} \Sigma_{g}^{+}\right)+\mathrm{O}\left({ }^{3} P\right) \rightarrow \mathrm{CO}\left(D^{1} \Delta^{-}\right)+\mathrm{C}\left({ }^{3} P\right)$ & $4.163 \times 10^{-13}$ & -0.541 & 36262 & Equation (12) of Ref. 1 \\
\hline $\mathrm{C}_{2}\left(d^{3} \Pi_{g}\right)+\mathrm{O}\left({ }^{3} P\right) \rightarrow \mathrm{CO}\left(X^{1} \Sigma^{+}\right)+\mathrm{C}\left({ }^{3} P\right)$ & $7.662 \times 10^{-12}$ & -1.259 & -14466 & Rate coefficient ${ }^{55}$ \\
\hline $\mathrm{O}_{2}\left(X^{3} \Sigma_{g}^{-}\right)+\mathrm{C}\left({ }^{3} P\right) \rightarrow \mathrm{CO}\left(a^{3} \Pi\right)+\mathrm{O}\left({ }^{3} P\right)$ & $9.606 \times 10^{-17}$ & 0 & 348 & Rate coefficient ${ }^{56}$ \\
\hline $\mathrm{O}_{2}\left(X^{3} \Sigma_{g}^{-}\right)+\mathrm{C}\left({ }^{3} P\right) \rightarrow \mathrm{CO}\left(a^{\prime 3} \Sigma^{+}\right)+\mathrm{O}\left({ }^{3} P\right)$ & $8.118 \times 10^{-17}$ & 0 & 1024 & Equation (12) of Ref. 1 \\
\hline $\mathrm{O}_{2}\left(X^{3} \Sigma_{g}^{-}\right)+\mathrm{C}\left({ }^{3} P\right) \rightarrow \mathrm{CO}\left(d^{3} \Delta\right)+\mathrm{O}\left({ }^{3} P\right)$ & $1.732 \times 10^{-16}$ & 0 & 1782 & Equation (12) of Ref. 1 \\
\hline $\mathrm{O}_{2}\left(X^{3} \Sigma_{g}^{-}\right)+\mathrm{C}\left({ }^{3} P\right) \rightarrow \mathrm{CO}\left(e^{3} \Sigma^{-}\right)+\mathrm{O}\left({ }^{3} P\right)$ & $9.291 \times 10^{-17}$ & 0 & 1919 & Equation (12) of Ref. 1 \\
\hline $\mathrm{O}_{2}\left(X^{3} \Sigma_{g}^{-}\right)+\mathrm{C}\left({ }^{3} P\right) \rightarrow \mathrm{CO}\left(D^{1} \Delta^{-}\right)+\mathrm{O}\left({ }^{3} P\right)$ & $6.314 \times 10^{-18}$ & 0 & 2127 & Equation (12) of Ref. 1 \\
\hline
\end{tabular}


NO have been implemented in CoRaM-MARS. The rate coefficients are due to Chernyi and Losev ${ }^{59}$ and to the UMIST database (http:// www.udfa.net). The processes involving $\mathrm{CN}$ have also been taken into account. The VRP has been used if necessary to derive the vibrational state-dependent rate coefficient. Some rate coefficients given under the modified Arrhenius form $k(T)=A T^{\alpha} e^{-\Delta E /\left(k_{B} T\right)}$ are given in Table III.

\section{Other collisional processes}

Additional processes involving carbonated ions and neutrals are now considered like charge exchange, excitation transfer, and reassociation (simultaneous neutral and charge exchange). Some of the required rate coefficients are reported in the UMIST database. The related values range between some $10^{-17}$ and $10^{-15} \mathrm{~m}^{3} \mathrm{~s}^{-1}$ and weakly depend on $T_{A}$.

Among the previously mentioned elementary processes, we have considered the dissociative recombination of $\mathrm{CO}^{+}, \mathrm{C}_{2}^{+}$, and $\mathrm{CN}^{+}$. The rate coefficients are taken from the work of Rosén et al. ${ }^{60}$ and Mezei et al. ${ }^{61}$ for $\mathrm{CO}^{+}$, Le Padellec et al. ${ }^{62}$ for $\mathrm{CN}^{+}$, and Mitchell ${ }^{63}$ for $\mathrm{C}_{2}^{+}$. The significance of dissociative recombination has already been put in evidence behind shock fronts. ${ }^{64}$ In addition, some excitation transfer processes between $\mathrm{CO}, \mathrm{NO}$, and $\mathrm{N}_{2}$ have been implemented in the model. The rate coefficients are due to Gorelov et al. ${ }^{38}$

The excited states of the molecular species can be dissociated under electron impact. We have used Eq. (8) of our paper devoted to air $^{1}$ to give the rate coefficient under the form of a modified Arrhenius law for the dissociation involving carbonated species.

All the collisional backward processes derived from the forward processes described above are finally included in the model. Each rate coefficient is determined using the detailed balance principle.

\section{Radiative processes}

We have taken into account molecular systems and atomic lines due to carbonated species. Table IV lists these additional data. Escape factors have been implemented. ${ }^{1}$ Except spontaneous emission, the model has also been enriched by the implementation of radiative recombination whose significance is obvious at low density. Equation (34) of our paper on air $^{1}$ based on the cross section due to Zel'dovich and Raizer ${ }^{65}$ has been used. Finally, the $\mathrm{C}^{+}$dielectronic recombination,

$$
\mathrm{C}^{+}+e^{-} \rightarrow \mathrm{C}\left({ }^{1} \mathrm{D}\right)+h \nu,
$$

is also implemented in the model with the rate coefficient determined by Nussbaumer and Storey. ${ }^{66}$

\section{RESULTS}

\section{A. Martian entry conditions}

During its atmospheric entry and before its final crash, the landing module Schiaparelli has interacted with atmospheric layers having different mixing ratios. Above an altitude of $\sim 130 \mathrm{~km}$, the $\mathrm{N}_{2}$ and $\mathrm{Ar}$ mixing ratios increase with altitude, while they have the same value as on the ground for lower altitudes. ${ }^{67}$ The composition is relatively well known since the Viking probe landing and has been recently confirmed by the Mars Science Laboratory mission. ${ }^{68}$ The mole fraction of $\mathrm{N}_{2}$ is equal to that of $\mathrm{Ar}$ at $2 \%$. A residual mole fraction is found for $\mathrm{O}_{2}$ and $\mathrm{CO}$ at values equal to $0.15 \%$ and $0.06 \%$, respectively. These
TABLE IV. Additional molecular systems and atomic lines implemented in CoRaMMARS with respect to CoRaM-AIR. ${ }^{1}$ References where the concerned Einstein coefficients can be found are given.

\begin{tabular}{lccc}
\hline \hline Species & Transitions & System/lines & References \\
\hline $\mathrm{CO}_{2}$ & $X^{1} \Sigma_{g}^{+} v^{\prime \prime}-X^{1} \Sigma_{g}^{+} v^{\prime}$ & Infrared & 76 \\
$\mathrm{CO}$ & $X^{1} \Sigma^{+} v^{\prime \prime}-X^{1} \Sigma^{+} v^{\prime}$ & Infrared & 77 \\
& $A^{1} \Pi-X^{1} \Sigma^{+}$ & Fourth positive & 77 \\
& $B^{1} \Sigma^{+}-X^{1} \Sigma^{+}$ & Hopfield-Birge & 77 \\
& $a^{\prime 3} \Sigma^{+}-a^{3} \Pi$ & Asundi & 11 \\
& $d^{3} \Delta-a^{3} \Pi$ & Triplet & 11 \\
& $b^{3} \Sigma^{+}-a^{3} \Pi$ & Third positive & 77 \\
$\mathrm{CO}^{+}$ & $B^{1} \Sigma^{+}-A^{1} \Pi$ & Angström & 11 \\
& $A^{2} \Pi-X^{2} \Sigma^{+}$ & Comet-tail & 77 \\
& $B^{2} \Sigma^{+}-X^{2} \Sigma^{+}$ & First negative & 77 \\
$\mathrm{CN}$ & $B^{2} \Sigma^{+}-A^{2} \Pi$ & Baldet-Johnson & 77 \\
& $A^{2} \Pi-X^{2} \Sigma^{+}$ & Red & 77 \\
& $B^{2} \Sigma^{+}-X^{2} \Sigma^{+}$ & Violet & 77 \\
$\mathrm{C}_{2}$ & $B^{2} \Sigma^{+}-A^{2} \Pi$ & Le Blanc & 77 \\
& $A^{1} \Pi_{u}-X^{1} \Sigma_{g}^{+}$ & Philips & 77 \\
& $D^{1} \Sigma_{u}^{+}-X^{1} \Sigma_{g}^{+}$ & Mulliken & 77 \\
& $b^{3} \Sigma_{g}^{-}-a^{3} \Pi_{u}$ & Ballik-Ramsay & 77 \\
& $d^{3} \Pi_{g}-a^{3} \Pi_{u}$ & Swan & 77 \\
$\mathrm{C}^{+}$ & $C^{1} \Pi_{g}-A^{1} \Pi_{u}$ & Deslandres-D'Azambuja & 77 \\
\hline \hline & $e^{3} \Pi_{g}-a^{3} \Pi_{u}$ & Fox-Herzberg & 77 \\
& $\mathrm{C}_{j} \rightarrow \mathrm{C}_{i<j}+h \nu$ & 1369 Lines & NIST \\
& $\mathrm{C}_{j}^{+} \rightarrow \mathrm{C}_{i<j}^{+}+h \nu$ & 11 Lines & NIST \\
\hline & & & \\
& & &
\end{tabular}

traces are due to the atmospheric chemistry induced by the solar irradiation. They are too weak to play a significant role. We have therefore assumed their influence negligible. The retained composition is therefore $96 \% \mathrm{CO}_{2}, 2 \% \mathrm{~N}_{2}$, and $2 \% \mathrm{Ar}$.

The most critical phase of the entry takes place before the deceleration peak, when the thermal flux between the shock layer and the TPS of the spacecraft is maximum. This peak heating $(\mathrm{PH})$ has been predicted around $70 \mathrm{~s}$ after the beginning of the entry phase, at an altitude of $\sim z_{0}=45 \mathrm{~km}$. The actual flight did not confirm these characteristics since they correspond to the plasma blackout phase. However, we have considered these conditions as respected. The module had a speed of $u_{0}=5300 \mathrm{~m} \mathrm{~s}^{-1}$ at this altitude. The local thermodynamic conditions have been reevaluated through the Mars Science Laboratory mission ${ }^{69}$ with respect to the Viking program results. ${ }^{70}$ The pressure, the temperature, and the specific mass at $z_{0}$ are $p_{0}=7.6 \mathrm{~Pa}, T_{A 0}=162 \mathrm{~K}$, and $\rho_{0}=2.45 \times 10^{-4} \mathrm{~kg} \mathrm{~m}^{-3}$, respectively. This corresponds to a mean molar mass of $43.4 \times 10^{-3} \mathrm{~kg} \mathrm{~mol}^{-1}$ compatible with the mixing ratio discussed above. In these flight conditions, the Mach number is $\mathcal{M}_{0}=26.4$.

Since flight data have been obtained under an altitude of $z_{0}=28.2 \mathrm{~km}$ after the blackout phase, ${ }^{71,72}$ the second trajectory point considered in our study corresponds to this low altitude (LA) where the thermodynamic conditions are $p_{0}=57 \mathrm{~Pa}, T_{A 0}=192 \mathrm{~K}$, and $\rho_{0}=1.54 \times 10^{-3} \mathrm{~kg} \mathrm{~m}^{-3}$. The speed was $u_{0}=2550 \mathrm{~m} \mathrm{~s}^{-1}$. In these flight conditions, the Mach number is $\mathcal{M}_{0}=11.7$. The complete entry conditions are summarized in Table $\mathrm{V}$. 
TABLE V. Entry conditions.

\begin{tabular}{lccccc}
\hline \hline & \multirow{3}{*}{ Altitude } & \multicolumn{3}{c}{ Speed } & \multicolumn{3}{c}{ Pressure Temperature Mach number } \\
Conditions & $z_{0}, \mathrm{~km}$ & $u_{0}, \mathrm{~m} \mathrm{~s}^{-1}$ & $p_{0}, \mathrm{~Pa}$ & $T_{A 0}, \mathrm{~K}$ & $\mathcal{M}_{0}$ \\
\hline (PH) & 45 & 5300 & 7.6 & 162 & 26.4 \\
(LA) & 28.2 & 2550 & 57 & 192 & 11.7 \\
\hline \hline
\end{tabular}

\section{B. Initial conditions}

In the (PH) or (LA) entry conditions, a shock layer is formed around the forward heatshield just behind a shock front having a negligible typical thickness. In a first approximation, the RankineHugoniot discontinuity equations can be assumed across the shock front. Electron temperature is assumed frozen since the flow speed is much lower than the electron speed of sound. As a result, the kinetic temperature $T_{A}(0)$, the pressure $p(0)$, and the Mach number $\mathcal{M}(0)$ of heavy particles just after the shock front before any chemical activity (at the abscissa $x=0$ in Secs. III D and III E) are given by

$$
\begin{gathered}
T_{A}(0)=\frac{\left[2+(\gamma-1) \mathcal{M}_{0}^{2}\right]\left[1-\gamma+2 \gamma \mathcal{M}_{0}^{2}\right]}{(\gamma+1)^{2} \mathcal{M}_{0}^{2}} T_{A 0}, \\
p(0)=\frac{1-\gamma+2 \gamma \mathcal{M}_{0}^{2}}{1+\gamma} p_{0}, \\
\mathcal{M}(0)=\sqrt{\frac{2+(\gamma-1) \mathcal{M}_{0}^{2}}{1-\gamma+2 \gamma \mathcal{M}_{0}^{2}}}
\end{gathered}
$$

where a mean value of $\gamma=1.3$ is used. This value allows us to match the Mach number sequence along the trajectory given by Tran and Beck. ${ }^{73}$ The values of $T_{A}(0), p(0)$, and $\mathcal{M}(0)$ are then the initial conditions of the system of nonlinear ordinary differential equations presented in Sec. III C.

\section{1D Eulerian code}

Since electrons and heavy particles are explicitly considered, the energy balance is applied for each type of particle. We reduce our study to the central streamline where the flow can be considered as one-dimensional along the $x$-axis in a first approximation. Denoting $e_{A}$ and $e_{e}$ the internal energy per unit volume, the related equations are written as

$$
\frac{d}{d x}\left(\frac{e_{A}}{\rho}+\frac{p_{A}}{\rho}+\frac{\rho_{A}}{\rho} \frac{u^{2}}{2}\right)=\frac{Q_{e \rightarrow A}-\varepsilon_{S E}-Q_{A, R D R}}{\rho u}
$$

for heavy particles and

$$
\frac{d}{d x}\left(\frac{e_{e}}{\rho}+\frac{p_{e}}{\rho}+\frac{\rho_{e}}{\rho} \frac{u^{2}}{2}\right)=\frac{-Q_{e \rightarrow A}-\varepsilon_{R D R}+Q_{A, R D R}}{\rho u}
$$

for electrons, where $p_{A}$ and $p_{e}$ are the pressure and $\rho_{A}$ and $\rho_{e}$ the specific mass of the heavies and electrons, respectively, with $\rho=\rho_{A}+\rho_{e}$. $Q_{e \rightarrow A}$ is the energy given per unit time and per unit volume by electrons to heavies through elastic and inelastic/superelastic processes. The energy lost by unit volume of the flow per unit time through radiation (spontaneous emission) excluding radiative recombination and dielectronic recombination is denoted $\varepsilon_{S E}$. The form taken by the energy balance equations (16) and (17) results from the high speed of the flow denoted $u$. Additional details may be found in Ref. 40 .

Equations (16) and (17) also account for the influence of the radiative recombination,

$$
A_{k}^{+}+e^{-} \rightarrow A_{i}+h \nu,
$$

for an atom $A$ and of the dielectronic recombination of type (12). These elementary processes have several influences on the balance equations (16) and (17). Indeed, they lead to the emission of a continuum since the elementary energy conservation is written as

$$
E_{k}+\frac{1}{2} m_{e} v_{e}^{2}=E_{i}+h \nu .
$$

As a result, a volumic emission coefficient $\varepsilon_{R D R}$ (expressed in $\mathrm{W} \mathrm{m}^{-3}$ ) has to be introduced in (17). This term corresponds to the radiation emitted during the capture of the electron by the ion during the process (18). Moreover, radiative and dielectronic recombinations lead to the decrease in the internal energy of the heavy particles since the recombination takes place. The energy $E_{k}-E_{i}$ is therefore lost. The related term is denoted $Q_{A, R D R}$ per unit volume per unit time and is introduced in the energy balance for heavies (16). Since the energy conservation equation of the flow is

$$
\frac{d}{d x}\left(\frac{e_{A}+e_{e}}{\rho}+\frac{p_{A}+p_{e}}{\rho}+\frac{u^{2}}{2}\right)=\frac{-\varepsilon_{S E}-\varepsilon_{R D R}}{\rho u},
$$

an additional term is required in Eq. (17) involving $Q_{A, R D R}$. This term can be considered as the influence of the redistribution of the thermal energy among fewer electrons when the recombination (12) or (18) takes place.

Previous Eqs. (16) and (17) are solved in coupling with the mass conservation

$$
\frac{d}{d x}(\rho u)=0
$$

the momentum conservation

$$
\frac{d}{d x}\left(p+\rho u^{2}\right)=0,
$$

and the balance equation relative to the species $X$ in a vibrational or electronic state $i$,

$$
\frac{d y_{X_{i}}}{d x}=\frac{m_{X_{i}}\left[X_{i, C R}\right]}{\rho u},
$$

using the DVODE library. ${ }^{74}$ In Eqs. (22) and (23), $p=p_{A}+p_{e}$ is the total pressure, $m_{X_{i}}$ is the mass of the species $X_{i}$, and $\left[X_{i, C R}\right]$ is the number density collisional-radiative source term resulting from the elementary processes discussed above.

\section{Analysis of the $(\mathrm{PH})$ conditions: $\mathcal{M}_{0}=\mathbf{2 6 . 4}$ \\ 1. Aerodynamic variables}

Figure 3 illustrates the aerodynamic variable distribution behind the shock front. Even if the thickness of the shock layer is only of the order of several centimeters, the distribution displayed on this figure is calculated until a quasiuniform zone corresponds to $\sim 10 \mathrm{~m}$. We can 


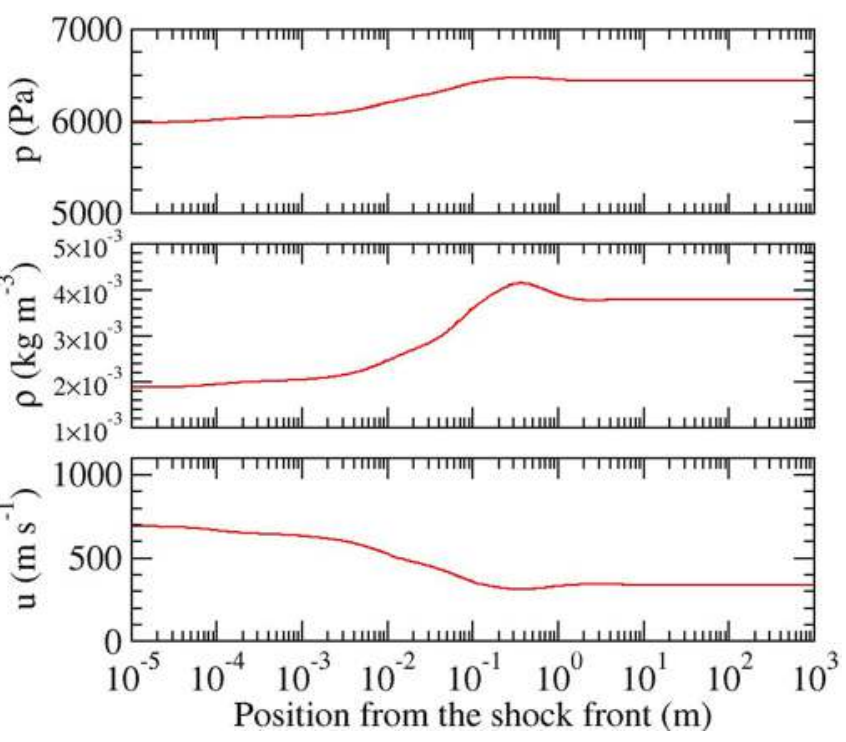

FIG. 3. Evolution behind the shock front (located at $x=0$ ) of the aerodynamic variables, pressure $p$, mass density $\rho$, and speed $u$ of the flow in the (PH) conditions.

see that the pressure, the mass density, and the speed reach just behind the shock front (located at $x=0$ ) values very close to those observed in this area. This means that chemistry induced by the heavy particle temperature $T_{A}$ behind the shock (close to $17000 \mathrm{~K}$ ) has a rather low influence on the aerodynamic variables. We can nevertheless observe this influence for $x \sim 10^{-2}-10 \mathrm{~m}$ where pressure and mass density are increasing, whereas speed is decreasing.

\section{Main characteristics of the chemistry}

This chemistry is clearly at work in Fig. 4. Indeed, the dissociation of the flow becomes significant at $x \sim 10^{-2} \mathrm{~m}$. The density of CO

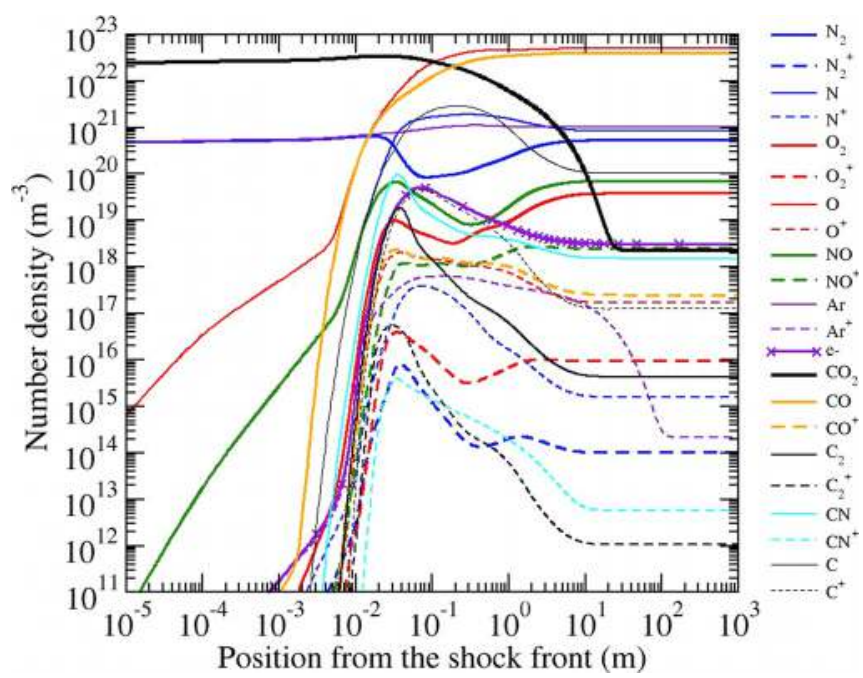

FIG. 4. Evolution behind the shock front of the density of the species in the (PH) conditions (neutrals in continuous lines and charged species in dashed lines). and $\mathrm{O}$ increase as well as the one of $\mathrm{N}$. This dissociation phase induces the formation of molecules not present in the incoming flow such as $\mathrm{NO}$ and molecular ions, a part of which is subsequently partially dissociated. This dissociation phase also leads to the formation of atomic ions particularly $\mathrm{C}^{+}$whose density equilibrates more or less the electron density. The following relaxation enables the formation of $\mathrm{NO}^{+}$ and $\mathrm{CO}^{+}$, leading to the electroneutrality of the flow with electrons. The temperature reached in this region is too weak to induce a significant ionization of Ar, whose influence could be neglected in a first approximation.

\section{Vibrational distributions and vibrational temperatures}

Except $\mathrm{Ar}^{+}, \mathrm{CO}_{2}$ is the slower species. In the present conditions, its relaxation requires $\sim 30 \mathrm{~m}$. This behavior is mainly due to the vibrational structure of this molecule. With its second (bending) mode whose states close to the dissociation limit are highly degenerated, the excited states behave like a reservoir when they are sufficiently populated. For $x>10^{-1} \mathrm{~m}$, they are indeed highly populated. But temperatures have significantly decreased, which still leads to the dissociation with lower rates. The dissociation is therefore slowed down but goes on anyway until the final steady state.

An illustration of this reservoirlike behavior is obvious in Figs. 5-7. These figures correspond to the Boltzmann plots of modes 1,2 , and 3, respectively. We see, in particular, in Fig. 6, for mode 2, the strong increase in the ratio between density and degeneracy for $x$ $\sim 10^{-1} \mathrm{~m}$. At the same location, this ratio for the mode 2 excited states close to the dissociation limit is higher than those of the other modes by a factor at least equal to 10 . Since the degeneracy of these states is $\left(v_{2}+1\right)$ and since $v_{2, \max }=66$, the population density is at least higher by a factor of 100 . We can therefore assert that the $\mathrm{CO}_{2}$ molecules in the flow mostly belong to the second (bending) mode.

These figures also illustrate the regime change for the distribution at $x \sim 10^{-3} \mathrm{~m}$. This location corresponds to a coupling from the excitation point of view between the states close to the ground state and

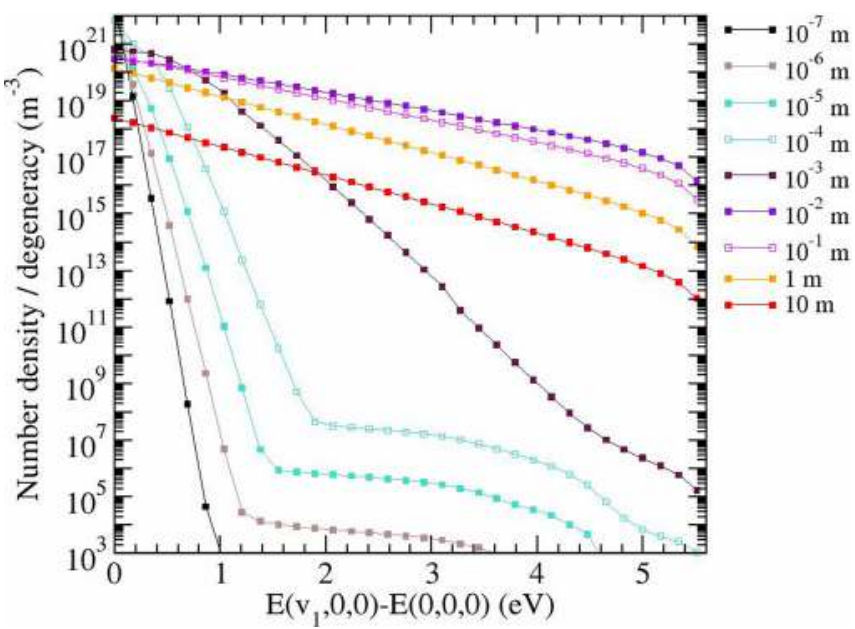

FIG. 5. Boltzmann plot of the $\mathrm{CO}_{2}\left(v_{1}, 0,0\right)$ states at $x=10^{-7}, \ldots, 10 \mathrm{~m}$ in the (PH) conditions. 


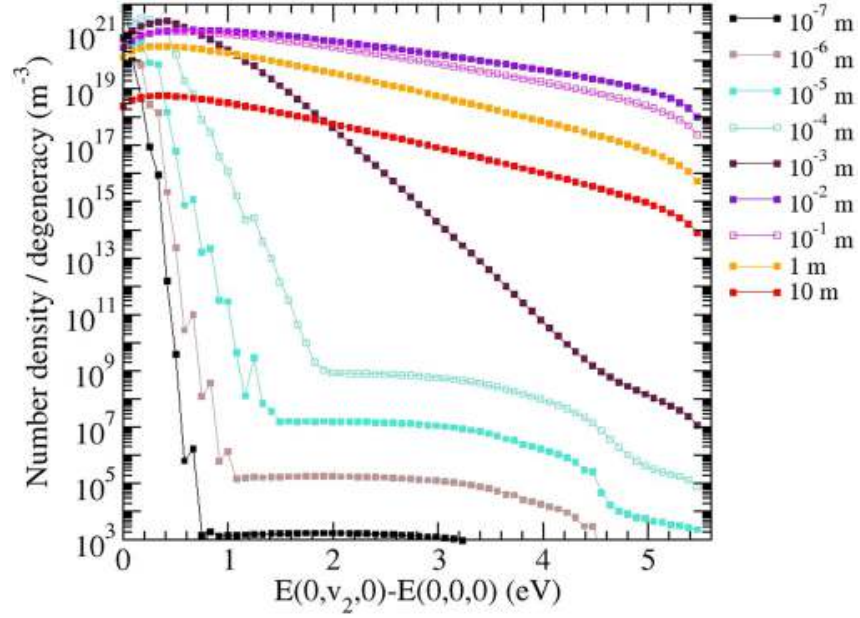

FIG. 6. Boltzmann plot of the $\mathrm{CO}_{2}\left(0, v_{2}, 0\right)$ states at $x=10^{-7}, \ldots, 10 \mathrm{~m}$ in the (PH) conditions.

those close to the dissociation limit. Systematically, the high-lying levels reach rapidly a relatively high excitation temperature characterized by a weakly negative slope of the mean square line interpolating the distribution. The relaxation time of the weakly excited levels is higher, and they remain weakly excited until $x \sim 10^{-3} \mathrm{~m}$ where the connection between the two distributions takes place. It is also interesting to note that stretching modes reach a quasiequilibrium distribution characterized by linear Boltzmann plots over its most part, whereas the bending mode departs from linear distribution on longer times.

Three types of vibrational temperatures can be postprocessed from the previous distribution to estimate the relevance of this concept. The vibrational temperature $T_{v i b \text {,inf }}\left(\mathrm{CO}_{2}\right)_{i}$ corresponds to the excitation temperature calculated from the first six vibrational excited states of mode $i$ such as

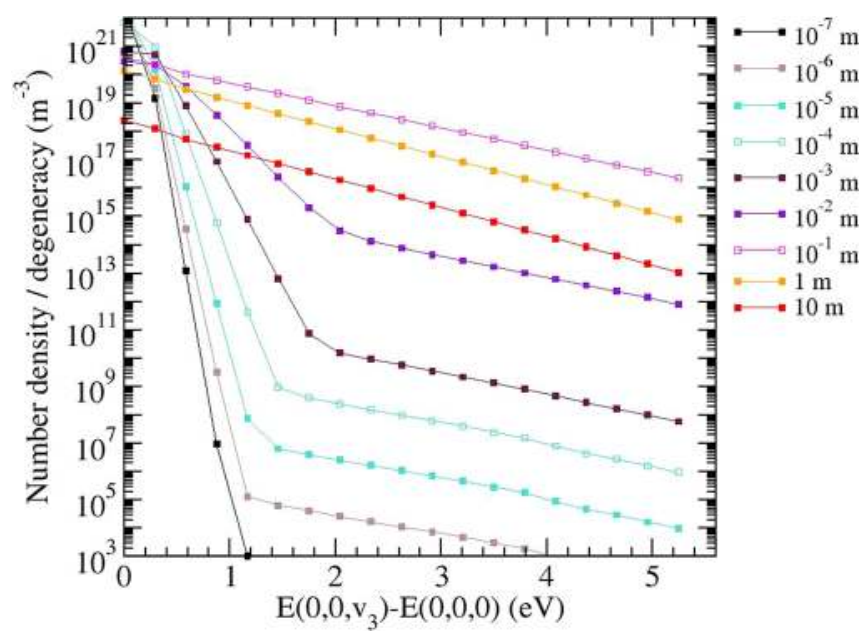

FIG. 7. Boltzmann plot of the $\mathrm{CO}_{2}\left(0,0, v_{3}\right)$ states at $x=10^{-7}, \ldots, 10 \mathrm{~m}$ in the (PH) conditions.

$$
T_{v}^{l}\left(\mathrm{CO}_{2}\right)_{i}=-\frac{1}{k_{B}\left[\frac{d}{d E(v)}\left(\ln \left[\mathrm{CO}_{2}(i, v)\right]\right)\right]_{l s l, 0 \leq v \leq 5}} .
$$

The vibrational temperature $T_{v i b \text { sup }}\left(\mathrm{CO}_{2}\right)_{i}$ corresponds to the excitation temperature calculated from the last six vibrational excited states of mode $i$ such as

$$
T_{v}^{u}\left(\mathrm{CO}_{2}\right)_{i}=-\frac{1}{k_{B}\left[\frac{d}{d E(v)}\left(\ln \left[\mathrm{CO}_{2}(i, v)\right]\right)\right]_{l s l, v_{\max }-5 \leq v \leq v_{\max }}} .
$$

The vibrational temperature $T_{v}^{E}\left(\mathrm{CO}_{2}\right)_{i}$ corresponds to the equilibrium distribution temperature required to obtain the vibrational energy density for mode $i$,

$$
\sum_{v}\left[\mathrm{CO}_{2}(i, v)\right] E(i, v)=\frac{\sum_{v}\left[\mathrm{CO}_{2}(i, v)\right] \sum_{v} g(i, v) E(i, v) e^{-\frac{E(i, v)}{k_{B} T_{v}^{E}\left(\mathrm{CO}_{2}\right)_{i}}}}{\sum_{v} g(i, v) e^{-\frac{E(i, v)}{k_{B} T_{v}^{(}\left(\mathrm{CO}_{2}\right)_{i}}}} .
$$

This definition corresponds to the classical definition of the vibrational temperature. Figures 8-10 display the evolution in space of these different temperatures for the symmetric stretching, the bending, and the asymmetric stretching modes of $\mathrm{CO}_{2}$, respectively. Electron temperature $T_{e}$ and heavy particle temperature $T_{A}$ are also displayed for comparison. We can see that the symmetric stretching and bending modes are satisfactorily coupled to each other, even if some discrepancies can be observed. This is mainly due to the Fermi resonance process (1) that easily promotes the excitation transfer between the modes considered. The vibrational temperatures $T_{v}^{l}\left(\mathrm{CO}_{2}\right)_{i}$ and $T_{v}^{E}\left(\mathrm{CO}_{2}\right)_{i}$ for modes $i=1$ and 2 present the same behavior. Starting from $T_{A 0}$, a maximum of around $11000 \mathrm{~K}$ is observed for $x \sim 10^{-2} \mathrm{~m}$. Then, a

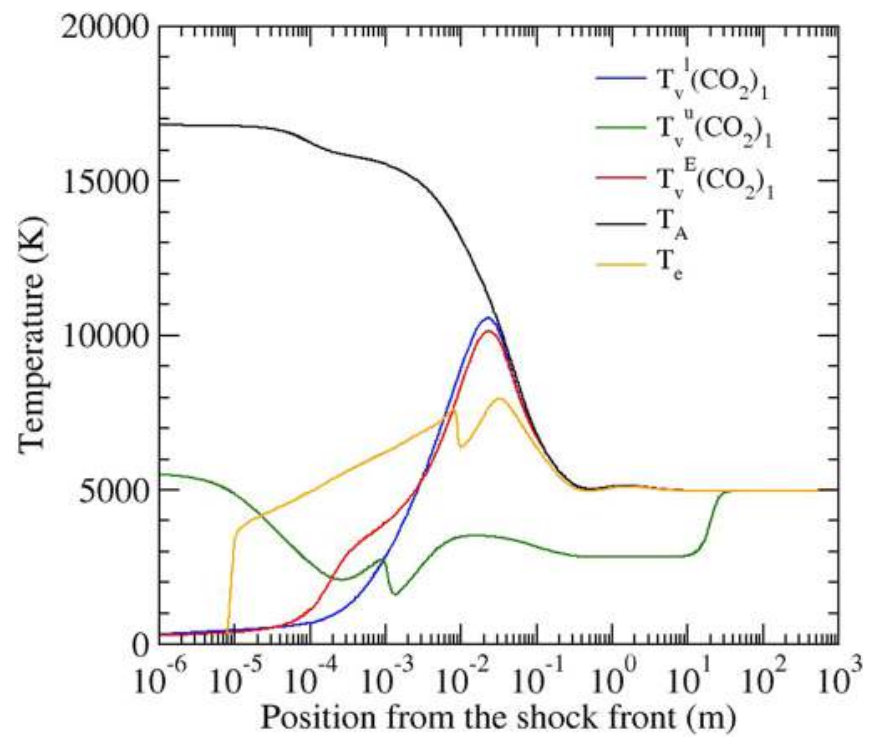

FIG. 8. Distribution of the vibrational temperatures for the symmetric stretching mode of $\mathrm{CO}_{2} . T_{A}$ refers to the heavy particle temperature and $T_{e}$ to the electron temperature. 


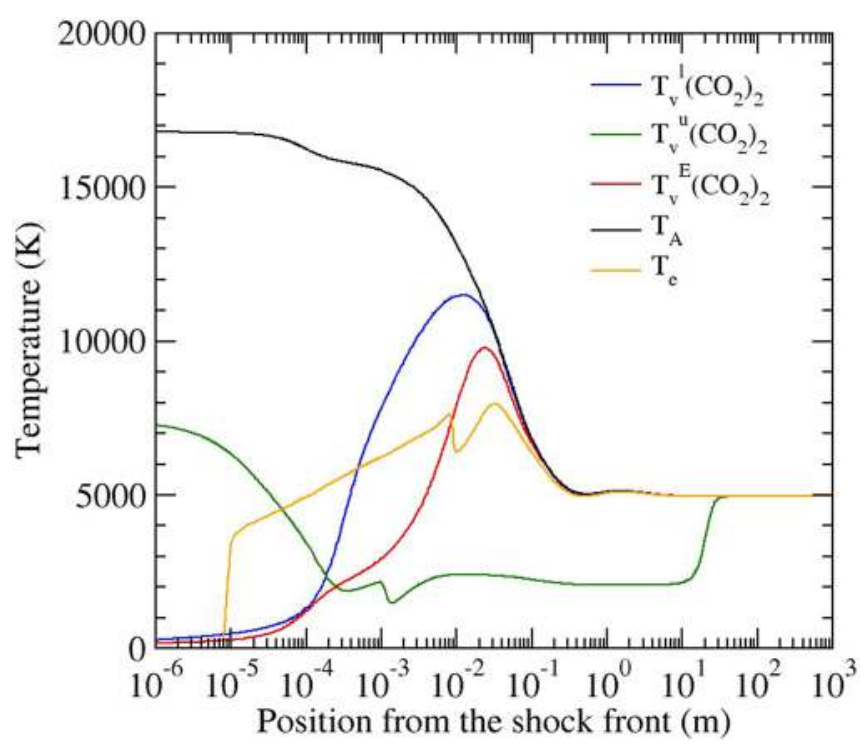

FIG. 9. Distribution of the vibrational temperatures for the bending mode of $\mathrm{CO}_{2} . T_{A}$ refers to the heavy particle temperature and $T_{e}$ to the electron temperature.

coupling with $T_{A}$ and $T_{e}$ occurs for $x \sim 10^{-1} \mathrm{~m}$ until the relaxation at $\sim 5000 \mathrm{~K}$ for $x>1 \mathrm{~m}$. The vibrational temperature $T_{v}^{u}\left(\mathrm{CO}_{2}\right)_{i}$ increases rapidly as already seen in Figs. 5-7. They are of the order of $6000 \mathrm{~K}$ for $x \sim 10^{-6} \mathrm{~m}$. Then, $T_{v}^{u}\left(\mathrm{CO}_{2}\right)_{3}$ remains uniform, whereas $T_{v}^{u}\left(\mathrm{CO}_{2}\right)_{i}$ decreases abruptly for $i=1$ and 2 . The third (asymmetric stretching) mode also behaves differently from the extremum point of view. The value obtained at $x \sim 10^{-2} \mathrm{~m}$ is quite lower than the ones obtained for modes 1 and 2. Globally, the third mode is difficult to excite. This is

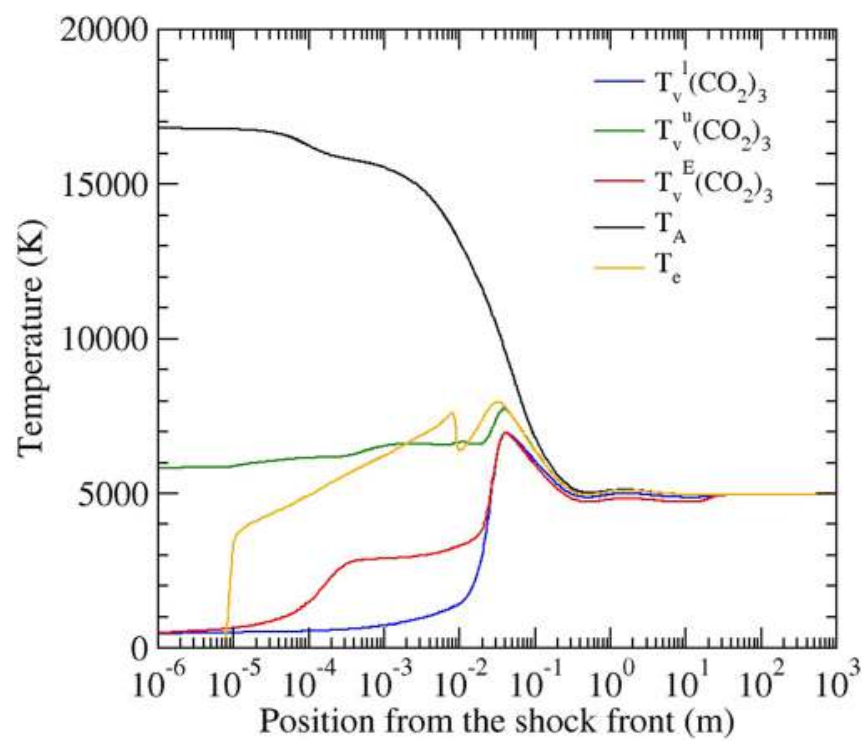

FIG. 10. Distribution of the vibrational temperatures for the asymmetric stretching mode of $\mathrm{CO}_{2} . T_{A}$ refers to the heavy particle temperature and $T_{e}$ to the electron temperature. the direct result of the characteristic energy of excitation higher than that for the other vibrational modes.

In the case of the experimental study of similar flows, for instance, produced in shock tubes, the vibrational energy is often considered as characterized by a vibrational temperature defined as the excitation temperature of the vibrational excited states close to the ground. Figures $8-10$ clearly show that this assumption is not necessarily obvious in the first centimeter downstream the shock front.

Moreover, Fig. 11 illustrates the comparison between the vibrational temperature defined by Eq. (26) for each mode and the global vibrational temperature $T_{v}^{E}\left(\mathrm{CO}_{2}\right)$ defined by extending the summation of Eq. (26) to the three modes. This comparison clearly shows that the second (bending) mode drives the global vibrational temperature of $\mathrm{CO}_{2}$. Indeed, $T_{v}^{E}\left(\mathrm{CO}_{2}\right)_{2}$ perfectly matches $T_{v}^{E}\left(\mathrm{CO}_{2}\right)$. This is due to the degeneracy of the bending mode which results from the ability of the molecule vibrationally excited in this mode to rotate. As already mentioned, the degeneracy of each vibrational level characterized by quantum number $v_{2}$ is then $v_{2}+1$. The ability to store numerous molecules in these states is quite high and the influence of $g(2, v)$ in the summations of Eq. (26) is significant. The energy is stored by difficulty in the third (asymmetric stretching) mode. The relaxation times are higher than those for the other modes. But this has no significant influence.

Heavy particle kinetic temperature $T_{A}$ decreases from the value of $T_{A}(0) \sim 17000 \mathrm{~K}$ resulting from the shock crossing to lower values of the order of $7000 \mathrm{~K}$ at $x \sim 10^{-1} \mathrm{~m}$. This is due to the energy pumping induced by the vibrational elementary processes. Electron temperature $T_{e}$ starts from $T_{A 0}$ and increases mainly through the $(\mathrm{Ve})$ processes and elastic collisions. The energy stored in translation is then mainly responsible for the vibrational excitation of the other molecules.

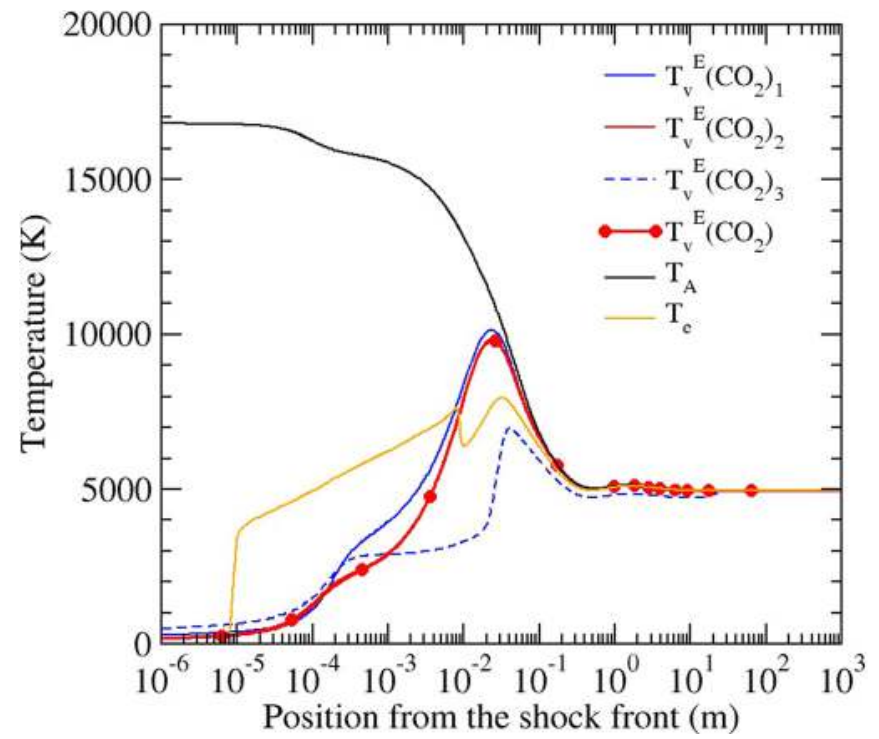

FIG. 11. Distribution of $T^{E}\left(\mathrm{CO}_{2}\right)_{i}$, the energy-defined vibrational temperatures for the different modes $i$ of $\mathrm{CO}_{2}$, and $T_{v}^{E}\left(\mathrm{CO}_{2}\right)$, the global vibrational temperature of $\mathrm{CO}_{2} . T_{A}$ refers to the heavy particle temperature and $T_{e}$ to the electron temperature. 


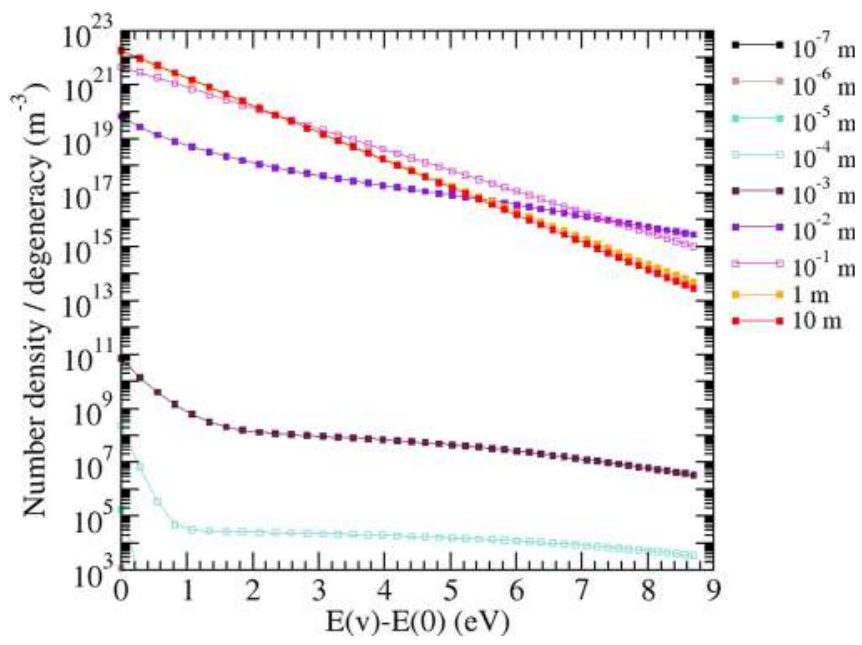

FIG. 12. The same as Fig. 5, but for $\mathrm{CO}$.

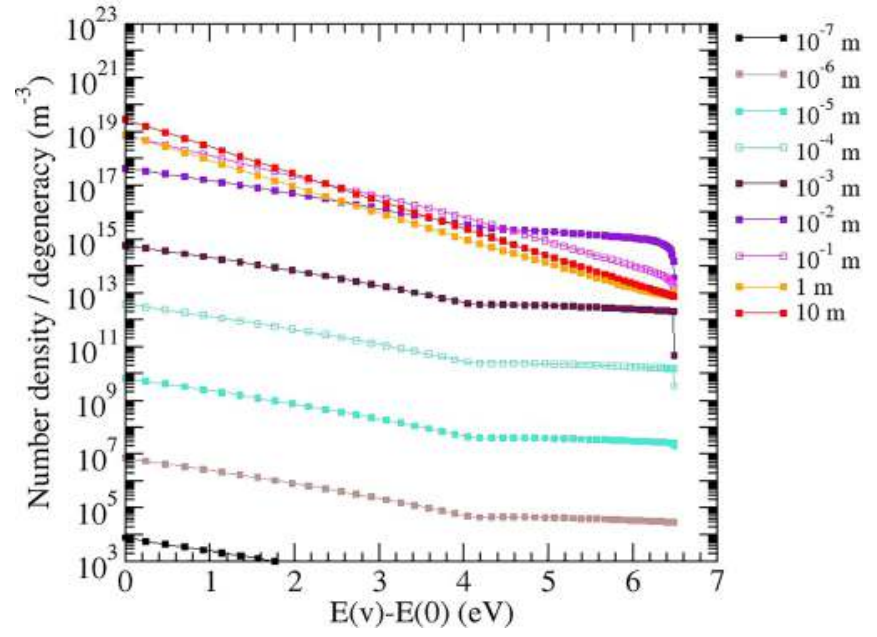

FIG. 13. The same as Fig. 12, but for NO.

\section{Molecular excited states}

Triplet states have been considered, but the related densities remain rather weak and do not participate fundamentally in the chemistry.

$\mathrm{CO}$ is the most important molecule in the flow in terms of density. We therefore present in Fig. 14 its density field including the first ten vibrational excited states of the $\mathrm{X}$ electronic state, as well as the one of $\mathrm{CO}^{+}$. We can see that the excited electronic states do not contribute significantly to the total carbon monoxide density. Except the $D^{1} \Delta^{-}, b^{3} \Sigma^{+}$, and $B^{1} \Sigma^{+}$states, the dissociation following the excitation phase around $x \sim 10^{-2} \mathrm{~m}$ leads to a decrease of two orders of magnitude in the population density of the states. This means that the radiative signature due to the systems listed in Table IV is mainly observed for $x \sim 10^{-2} \mathrm{~m}$. The figure also displays the distribution of the $\mathrm{CO}^{+}$ population density whose values remain rather weak.

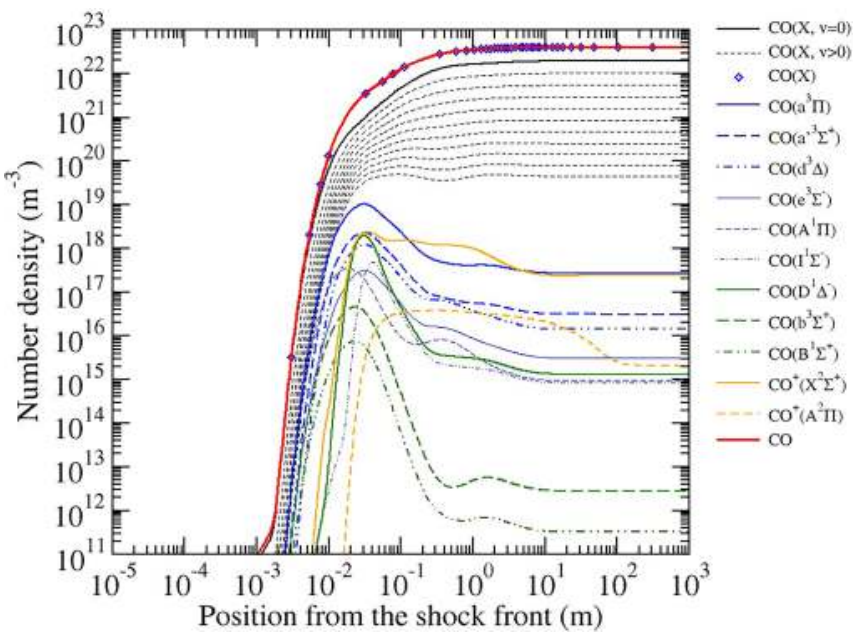

FIG. 14. The same as Fig. 4, but for the electronic states of $\mathrm{CO}$ and $\mathrm{CO}^{+}$ 


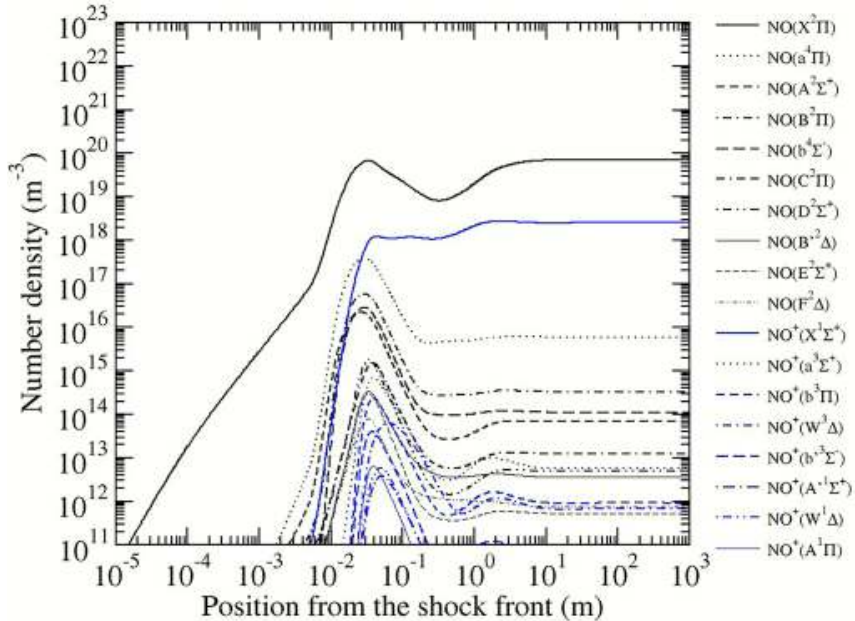

FIG. 15. The same as Fig. 4, but for the electronic states of $\mathrm{NO}$ and $\mathrm{NO}^{-}$

For $x<1 \mathrm{~m}$, the main ionic species is $\mathrm{C}^{+}$and is replaced by $\mathrm{NO}^{+}$at a higher distance from the shock front. We consequently present in Fig. 15 the distribution of the population density of $\mathrm{NO}^{+}$as well as those of NO. In the two cases, the excited states are weakly populated. This results mainly from the temperature in the region $x>1 \mathrm{~m}$ whose value does not exceed $5000 \mathrm{~K}$.

\section{E. Analysis of the (LA) conditions: $\mathcal{M}_{0}=11.7$}

To obtain information on the flow in the conditions of the data collected after the blackout phase, we have chosen to consider the (LA) flight conditions (see Table V). Figure 16 illustrates in these conditions the distribution of the species in the flow from the shock front. We can see that the dissociation degree is very weak. Indeed, at $x=0.1 \mathrm{~m}$, its value is $\sim 10^{-6}$. This is mainly due to the

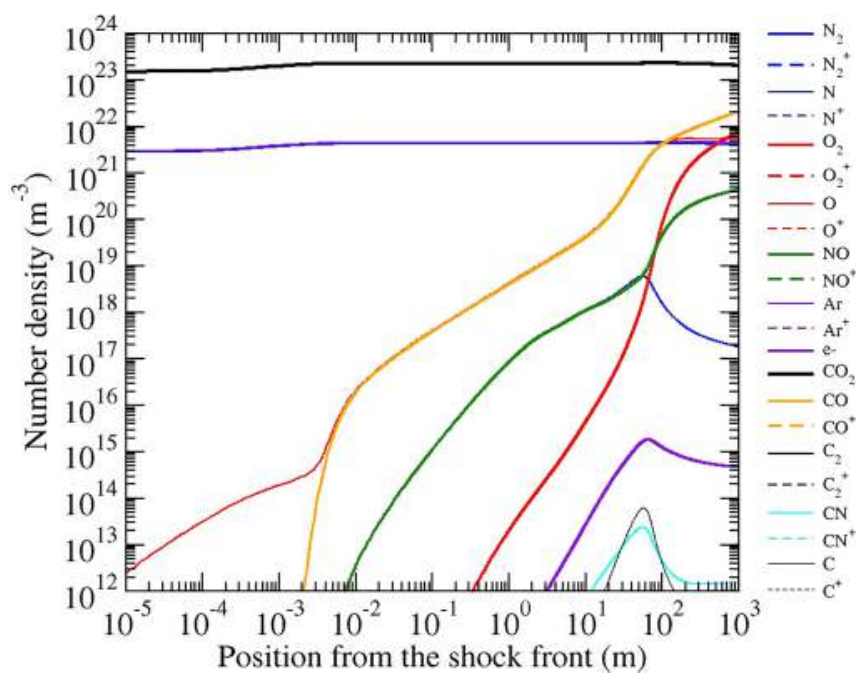

FIG. 16. Evolution behind the shock front of the density of the species in the (LA) conditions (neutrals in continuous lines and charged species in dashed lines). temperature and the pressure behind the shock front whose values are close to $4000 \mathrm{~K}$ and $9000 \mathrm{~Pa}$, respectively. No ion type can be significantly produced in such conditions. The weak temperature level extends the time scales over which the main processes take place. As a result, a no physical position of $\sim 100 \mathrm{~m}$ from the shock front is necessary to obtain a significant dissociation degree. Figure 17 displays the distribution of the kinetic temperature $T_{A}$ within the flow. After the shock front at a value close to $4000 \mathrm{~K}, T_{A}$ decreases until $\sim 3000 \mathrm{~K}$ for $x>4 \times 10^{-3}$ m due to the vibrational pumping.

In this figure is also displayed the distribution of the vibrational temperature of the $\mathrm{CO}_{2}$ modes. We can see that the first and the second vibrational modes remain coupled as in the case of the (PH) conditions. The coupling is perhaps better since the difference between $T_{v}^{l}\left(\mathrm{CO}_{2}\right)$ and $T_{v}^{E}\left(\mathrm{CO}_{2}\right)$ is lower for each mode. The discrepancies observed with mode 3 are higher in the present case than for the $(\mathrm{PH})$ conditions. Indeed, the evolution is delayed by three orders of magnitude with a final coupling observed at $x \sim 10^{1} \mathrm{~m}$, whereas the coupling between modes 1 and 2 is obvious at $x \sim 10^{-2} \mathrm{~m}$.

This figure illustrates the distribution of the vibrational temperature of the ground state of $\mathrm{NO}, \mathrm{N}_{2}$, and $\mathrm{CO}$ in terms of vibrational energy storage defined by Eq. (26). Figure 13 shows that NO is produced with a high vibrational temperature in the $(\mathrm{PH})$ conditions since the Boltzmann plots around the ground vibrational state have a negative slope close to 0 . NO is therefore directly produced in excited vibrational states. This excitation of the products results from the (VRP) and from the main channel of production of NO by neutral (Zel'dovich) exchange $\mathrm{N}_{2}+\mathrm{O} \rightarrow \mathrm{NO}+\mathrm{N}$. In the present (LA) conditions, NO is still produced with a high vibrational excitation and the vibrational temperature calculated using Eq. (26) is close to $10000 \mathrm{~K}$ before the complete coupling for $x>10^{1} \mathrm{~m}$ at $\sim 3000 \mathrm{~K}$. For $\mathrm{N}_{2}$, the distribution of the vibrational temperature illustrates the quasiresonance of $\omega_{e}$ between $\mathrm{N}_{2}$ and the third mode of $\mathrm{CO}_{2}$. Since the vibrational excitation of $\mathrm{N}_{2}$ is weak, the coupling is obtained with $T_{v}^{l}\left(\mathrm{CO}_{2}\right)_{3}$ and not with $T_{v}^{E}\left(\mathrm{CO}_{2}\right)_{3}$. Finally, the vibrational excitation of $\mathrm{CO}$ is intermediate as a result of the influence of the different elementary processes.

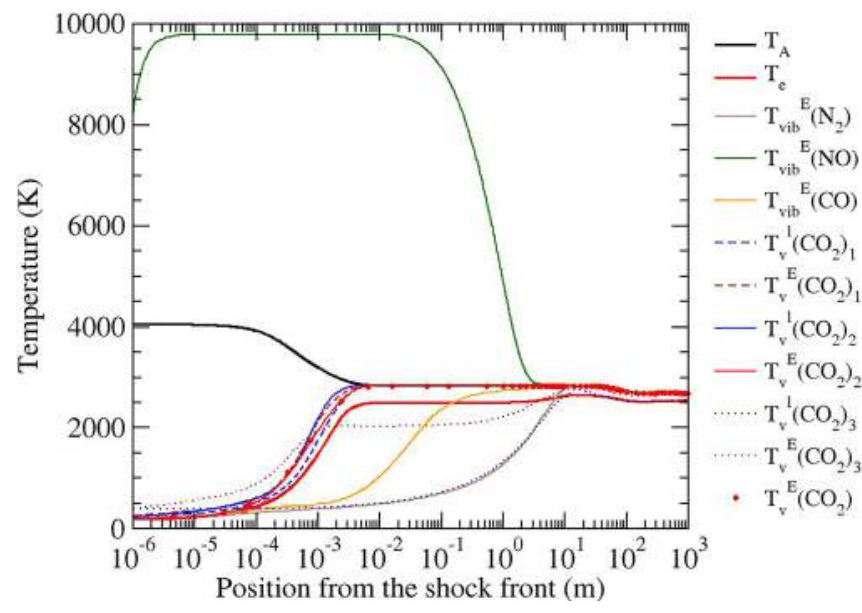

FIG. 17. Evolution behind the shock front of different characteristic temperatures in the $(\mathrm{LA})$ conditions. 
The final coupling is more or less obtained at locations very far from the shock front. Of course, since the shock layer has a thickness of several centimeters, it is obvious that this coupling will not be obtained. The edge of the boundary layer will be therefore out of thermochemical equilibrium.

\section{F. Relative role of electrons and heavies in the collisional processes}

Due to their different efficiency in terms of collisions and to the thermal nonequilibrium in the flow, electrons and heavy particles have been separately considered in the present model. For the (LA) conditions studied in Sec. IIIE, electrons clearly do not play a significant role. Indeed, electron density and temperature are too weak to have any influence on the chemistry. Conversely, for the $(\mathrm{PH})$ conditions, the role played by electrons is clearly stronger. However, their density and temperature have to be high enough. Since electron density is 0 upstream, the vibrational excitation and therefore the dissociation degree are mainly driven by the heavy particles in the first centimeters of the flow. For positions farther from the shock front, whereas the vibrational excitation is already significant, electrons have reached high temperature and density. Then, they act on the vibrational distributions.

\section{CONCLUSION}

In this paper, we have reported the elaboration and the implementation in a $1 \mathrm{D}$ Eulerian CFD code of the collisional-radiative model CoRaM-MARS especially developed for Martian entries. This model takes into account $\mathrm{CO}_{2}, \mathrm{~N}_{2}$, and Ar as well as all the species possibly produced when chemistry takes place. The model is vibrationally and electronically specific with 445 vibrational states (electronic ground states of neutral molecules only and vibrational excitation of $\mathrm{CO}_{2}$ considered in its three modes without preferential coupling) and 1139 electronic states, respectively. A complete set of forward and backward elementary processes is considered involving excitation vibrational processes, dissociation, electronic excitation, ionization, neutral and charge exchanges, excitation transfer, reassociation, dissociative recombination, dielectronic and radiative recombination, and spontaneous emission.

In relation to the EXOMARS mission of 2016 and for the analysis of the flight of the Schiaparelli module, we have studied the postshock flow induced by the atmospheric entry for two Mach number conditions. The first situation corresponds to the peak heating at the surface of the thermal protection system of the module. The second situation corresponds to conditions just after the blackout phase for which measurements by different sensors have been performed and are currently under analysis. We have particularly focused our attention on the first situation because it enables the formation of the greater part of the species involved in the model. All calculations have been performed assuming a discontinuity at the shock front location driven by the Rankine-Hugoniot equations.

For the first situation, the flow is in thermochemical nonequilibrium over some centimeters. For $\mathrm{CO}_{2}$, the second (bending) mode is the most efficient from the energy storage point of view. The Fermi resonance ensures a very good coupling between this mode and the first (symmetric stretching) mode without a significant difference in terms of vibrational temperature. Even if the triplet states of $\mathrm{CO}_{2}$ have been considered, they do not play a significant role. The electron density reaches rapidly significant values to play a role in the chemistry. The dissociation degree is also significant with $\mathrm{O}$ as major atomic species. For $\mathrm{NO}$ and $\mathrm{O}_{2}$ whose formation is mainly due to neutral exchange mechanisms, the vibrational excitation is strong very close to the shock front.

About the second situation at a lower Mach number, the dissociation degree remains very weak even far from the shock front. Except for this lower dissociation degree and the lower excitation resulting from the lower value of the specific energy, the conclusions previously highlighted above at a high Mach number are globally similar. All these results will support the interpretation of the measurements performed using the different sensors embedded aboard the module.

\section{ACKNOWLEDGMENTS}

The authors acknowledge the French Spatial Agency "Centre National d'Etudes Spatiales" and the "Région Haute-Normandie" for their financial support. The authors also acknowledge (1) Dr. Vincenzo Laporta for the data related to vibrational excitation and dissociation rate coefficients of $\mathrm{N}_{2}(X, v), \mathrm{O}_{2}(X, v), \mathrm{NO}(X, v)$, and $\operatorname{CO}(X, v)$ under electron impact and (2) Dr. Philippe Rivière from the EM2C laboratory, CentraleSupelec and Dr. Yacine Babou for the data related to the Einstein coefficients of the radiative systems of $\mathrm{CO}, \mathrm{C}_{2}, \mathrm{CN}$, and $\mathrm{CO}^{+}$. A part of the research leading to these results has received funding from the European Community's 7th Framework Programme (FP7/2007/2013) under Grant Agreement No. 242311.

\section{REFERENCES}

${ }^{1}$ J. Annaloro and A. Bultel, Phys. Plasmas 21, 123512 (2014).

${ }^{2}$ A. L. Brun and P. Omaly, "Investigation of radiative heat fluxes for Exomars entry in the Martian atmosphere," in ESA Special Publication Vol. 689 (ESA, 2011), p. 22.

${ }^{3}$ S. Tashkun, V. Perevalov, J.-L. Teffo, L. Rothman, and V. tyuterev, J. Quant. Spectrosc. Radiat. Transfer 60, 785-801 (1998).

${ }^{4}$ J. Annaloro, A. Bultel, and P. Omaly, AIAA Paper No. 2011-3954, 2011.

5. Annaloro, A. Bultel, and P. Omaly, J. Phys.: Conf. Ser. 511, 012053 (2014).

${ }^{6}$ T. Kozak and A. Bogaerts, Plasma Sources Sci. Technol. 24, 015024 (2015).

${ }^{7}$ T. Silva, M. Grofulovic, B. Klarenaar, A. Morillo-Candas, O. Guaitella, R. Engeln, C. Pintassilgo, and V. Guerra, Plasma Sources Sci. Technol. 27, 015019 (2018).

${ }^{8}$ A. Berthelot and A. Bogaerts, Plasma Sources Sci. Technol. 26, 115002 (2017).

${ }^{9}$ Y. Babou, "Transferts radiatifs dans les plasmas de mélange $\mathrm{CO}_{2}-\mathrm{N}_{2}$ : Base de données spectroscopiques, étude expérimentale et application aux rentrées atmosphériques," Ph.D. thesis (Laboratoire EM2C, Ecole Centrale Paris, 2007).

${ }^{10}$ K. P. Huber and G. Herzberg, Molecular Spectra and Molecular Structure (Van Nostrand Reinhold Company, 1979).

${ }^{11}$ M. L. da Silva, "Simulation des propriétés radiatives du plasma entourant un véhicule traversant une atmosphère planétaire à vitesse hypersonique: Application à la planète Mars," Ph.D. thesis (Laboratoire ICARE, Université d'Orléans, 2004).

${ }^{12}$ P. J. Bruna and J. S. Wright, J. Phys. Chem. 96, 1630-1640 (1992).

${ }^{13}$ J. P. Maier and M. Rösslein, J. Chem. Phys. 88, 4614-4620 (1988).

${ }^{14}$ C. Petrongolo, P. J. Bruna, and S. D. Peyerimhoff, J. Chem. Phys. 74, 4594-4602 (1981).

${ }^{15}$ R. Wang, Z. H. Zhu, and C. L. Yang, J. Mol. Struct. 571, 133-138 (2001).

${ }^{16}$ K. A. Peterson, J. Chem. Phys. 102, 262-270 (1995).

${ }^{17}$ R. Polak and J. Fiser, Spectrochim. Acta, Part A 58, 2029-2041 (2002).

${ }^{18} \mathrm{P}$. H. Krupenie, "The band spectrum of carbon dioxide," Technical Report No. NSRDS-NBS-5 (1966).

${ }^{19} \mathrm{~K}$. Okada and S. Iwata, J. Chem. Phys. 112, 1804-1808 (2000). 
${ }^{20}$ L. Pietanza, G. Colonna, G. D’Ammando, A. Larrichiuta, and M. Capitelli, Phys. Plasmas 23, 013515 (2016).

${ }^{21}$ L. Pietanza, G. Colonna, and M. Capitelli, Plasma Sources Sci. Technol. 27, 095004 (2018)

${ }^{22}$ D. Bruno, M. Capitelli, F. Esposito, S. Longo, and P. Minelli, Chem. Phys. Lett. 360, 31-37 (2002)

${ }^{23}$ M. Panesi, R. L. Jaffe, D. Schwenke, and T. E. Magin, J. Chem. Phys. 138, 044312 (2013).

${ }^{24}$ M. Panesi, A. Munafo, T. E. Magin, and R. L. Jaffe, Phys. Rev. E 90, 013009 (2014).

${ }^{25}$ V. Joly and A. Roblin, Aerosp. Sci. Technol. 3, 229-238 (1999).

${ }^{26}$ K. F. Herzfeld, J. Chem. Phys. 47, 743-752 (1967).

27. A. Blauer and G. R. Nickerson, AIAA Paper No. 74-536, 1974.

${ }^{28}$ R. N. Schwartz, Z. I. Slawsky, and K. F. Herzfeld, J. Chem. Phys. 20, 1591-1599 (1952).

${ }^{29}$ Y. Itikawa, J. Phys. Chem. Ref. Data 31, 749-767 (2002).

${ }^{30}$ A. Fridman, Plasma Chemistry (Cambridge University Press, 2008).

${ }^{31}$ M. L. da Silva, V. Guerra, and J. Loureiro, J. Thermophys. Heat Transfer 21, 40-49 (2007).

${ }^{32}$ M. Capitelli, C. Ferreira, B. Gordiets, and A. Osipov, Plasma Kinetics in Atmospheric Gases (Springer, 2000).

${ }^{33}$ I. Armenise, M. Capitelli, G. Colonna, and C. Gorse, J. Thermophys. Heat Transfer 10, 397-405 (1996).

${ }^{34}$ V. Laporta, R. Celiberto, and J. M. Wadehra, Plasma Sources Sci. Technol. 21, 055018 (2012).

${ }^{35}$ V. Laporta, C. M. Cassidy, J. Tennyson, and R. Celiberto, Plasma Sources Sci. Technol. 21, 045005 (2012).

${ }^{36}$ V. Laporta, D. Little, R. Celiberto, and J. Tennyson, Plasma Sources Sci. Technol. 23, 065002 (2014).

${ }^{37}$ C. Park, AIAA Paper No. 2008-1446, 2008.

${ }^{38}$ V. A. Gorelov, M. K. Gladyshev, A. Y. Kireev, V. G. Tchebureev, and S. V. Shilenkov, "Non equilibrium ionization and radiation behind shock wave in Martian atmosphere," in ESA Special Publication Vol. 426 (ESA, 1998), pp. $429-436$.

${ }^{39}$ J. Lecointre, D. S. Belic, H. Cherkani-Hassani, J. J. Jureta, and P. Defrance, J. Phys. B 39, 3275-3297 (2006).

${ }^{40}$ A. Bultel and J. Annaloro, Plasma Sources Sci. Technol. 22, 025008 (2013).

${ }^{41}$ O. E. Krivonosova, S. A. Losev, V. P. Nalivayko, Yu. K. Mukoseev, and O. P. Shatalov, Plasma Chem. Energoatomizdat 14, 3-31 (1987) (in Russian).

${ }^{42} \mathrm{~J}$. Annaloro, "Modèles collisionnels-radiatifs appliqués aux situations d'entrée atmosphérique martienne et terrestre," Ph.D. thesis (CORIA, Université de Rouen, 2013).

${ }^{43}$ M. Capitelli, G. Colonna, and F. Esposito, J. Phys. Chem. A 108, 8930-8934 (2004).

${ }^{44}$ F. Esposito, I. Armenise, G. Capitta, and M. Capitelli, Chem. Phys. 351, 91-98 (2008).

${ }^{45}$ F. Esposito, I. Armenise, and M. Capitelli, Chem. Phys. 331, 1-8 (2006).

${ }^{46} \mathrm{~S}$. T. Surzhikov, "Electronic excitation in air and carbon dioxide gas," Technical Report No. 162 (DTIC Document, 2009).

${ }^{47}$ G. N. Zalogin, P. V. Kozlov, L. A. Kuznetsova, S. A. Losev, V. N. Makarov, Y. V. Romanenko, and S. T. Surzhikov, Tech. Phys. 46, 654-661 (2001).

${ }^{48}$ R. Riahi, P. Teulet, N. Jaidane, and A. Gleizes, Eur. Phys. J. D 56, 67-72 (2010).

${ }^{49}$ R. Olszewski, P. Wolinski, and M. Zubek, Chem. Phys. Lett. 297, 537-542 (1998).

${ }^{50}$ M. J. Brunger and S. J. Buckman, Phys. Rep. 357, 215-458 (2002).

${ }^{51}$ C. Park, AIAA Paper No. 2008-1206, 2008.
${ }^{52}$ R. S. Freund, R. C. Wetsel, and R. J. Shul, Phys. Rev. A 41, 5861-5868 (1990).

${ }^{53}$ H. W. Drawin, Report No. DPh-PFC/SRFC-383 (1966).

${ }^{54}$ J. Annaloro, V. Morel, A. Bultel, and P. Omaly, Phys. Plasmas 19, 073515 (2012).

${ }^{55}$ A. Aliat, Physica A 387, 4163-4182 (2008).

${ }^{56}$ G. P. Smith, D. M. Golden, M. Frenklach, N. W. Moriarty, B. Eiteneer, M. Goldenberg, C. T. Bowman, R. K. Hanson, S. Song, W. C. Gardiner, Jr., V. V. Lissianski, and Z. Qin, see http://combustion.berkeley.edu/gri-mech/version30/ text $30 . \mathrm{html}$ version30/text30.html for information about the rate coefficient of the O2-C exchange, 2016.

${ }^{57}$ E. Wigner and E. E. Witmer, Z. Phys. 51, 859-886 (1928).

${ }^{58}$ A. Collins, D. Dominey, and T. Swan, "Review of the gaseous oxidation of pyrocarbon and of the Boudouard reaction," Technical Report No. 1588 (Central Electricity Generating Board, Berkeley (England), Berkeley Nuclear Labs., 1970).

${ }^{59}$ G. G. Chernyi and S. A. Losev, ISTC Report No. 036-96 (1999).

${ }^{60}$ S. Rosen, P. Peverall, M. Larsson, A. LePadellec, J. Semaniak, A. Larson, C. Stromholm, W. J. van der Zande, H. Danared, and G. H. Dunn, Phys. Rev. A 57, 4462-4471 (1998).

${ }^{61}$ J. Z. Mezei, R. D. Backodissa-Kiminou, D. E. Tudorache, V. Morel, K Chakrabarti, O. Motapon, O. Dulieu, J. Robert, W.-U. Tchang-Brillet, A. Bultel, X. Urbain, J. Tennyson, K. Hassouni, and I. F. Schneider, Plasma Sources Sci. Technol. 24, 035005 (2015).

${ }^{62}$ A. Le Padellec, J. B. A. Mitchell, A. Al-Khalili, H. Danared, A. Kallberg, A. Larson, S. Rosén, M. af Ugglas, L. Viktor, and M. Larsson, J. Chem. Phys. 110, 890 (1999).

${ }^{63}$ J. B. A. Mitchell, Phys. Rep. 186, 215-248 (1990).

${ }^{64}$ A. Bultel, J. Annaloro, and M.-C. Druguet, EPJ Web Conf. 84, 06005 (2015).

${ }^{65}$ Y. B. Zel'dovich and Y. P. Raizer, Physics of Shock Waves and HighTemperature Hydrodynamic Phenomena (Dover, Mineola, 2002).

${ }^{66}$ H. Nussbaumer and P. J. Storey, Astron. Astrophys., Suppl. Ser. 56, 293-312 (1984).

${ }^{67}$ P. Mahaffy, M. Benna, M. Elrod, R. Yelle, S. Bougher, S. Stone, and B. Jakosky, Geophys. Res. Lett. 42, 8951, https://doi.org/10.1002/2015GL065329 (2015).

${ }^{68}$ P. Mahaffy, C. Webster, S. Atreya, H. Franz, M. Wong, P. Conrad, D. Harpold, J. Jones, L. Leshin, H. Manning, T. Owen, R. Pepin, S. Squyres, M. Trainer, and MSL Science Team, Science 341, 263 (2013).

${ }^{69}$ C. Holstein-Rathlou, A. Maue, and P. Withers, Planet. Space Sci. 120, 15-23 (2016).

${ }^{70}$ A. Seiff and D. Kirk, J. Geophys. Res. 82, 4364-4378, https://doi.org/10.1029/ JS082i028p04364 (1977).

${ }^{71}$ A. Gulhan, T. Thiele, F. Siebe, R. Kronen, and T. Schleutker, J. Spacecr. Rockets 56, 68-81 (2019).

${ }^{72}$ A. Gulhan, T. Thiele, F. Siebe, and R. Kronen, Space Sci. Rev. 214, 12 (2018).

${ }^{73}$ P. Tran and J. Beck, "Exomars entry demonstrator module aerodynamics," in ESA Special Publication Vol. 692 (ESA, 2011), pp. 3.1-3.10

${ }^{74}$ P. N. Brown, G. D. Byrne, and A. C. Hindmarsh, "VODE: A variablecoefficient ODE solver," SIAM J. Sci. Stat. Comput. 10, 1038-1051 (1989).

${ }^{75}$ A. Chiroux de Gavelle de Roany, C. Flament, J. W. Rich, and V. V. Subramaniam, AIAA J. 31, 119-128 (1993).

${ }^{76}$ L. Rothman, I. Gordon, R. Barber, H. Dothe, R. Gamache, A. Goldman, V. Perevalov, S. Tashkun, and J. Tennyson, J. Quant. Spectrosc. Radiat. Transfer 111, 2139-2150 (2010)

${ }^{77}$ Y. Babou, P. Rivière, M.-Y. Perrin, and A. Soufiani, J. Quant. Spectrosc. Radiat. Transfer 110, 89-108 (2009). 